Article

\title{
Double Role of Diphenylpyridine Derivatives as Fluorescent Sensors for Monitoring Photopolymerization and the Determination of the Efficiencies of the Generation of Superacids by Cationic Photoinitiators
}

\author{
Monika Topa ${ }^{1}$, Filip Petko ${ }^{2}$, Mariusz Galek ${ }^{2}$ and Joanna Ortyl 1,2,*(D) \\ 1 Faculty of Chemical Engineering and Technology, Cracow University of Technology, Warszawska 24, \\ 30-155 Cracow, Poland; monika.topa@doktorant.pk.edu.pl \\ 2 Photo HiTech Ltd., Bobrzyńskiego 14, 30-348 Cracow, Poland; filip.petko@photohitech.com (F.P.); \\ mariusz.galek@photohitech.com (M.G.) \\ * Correspondence: jortyl@chemia.pk.edu.pl
}

Received: 1 May 2020; Accepted: 26 May 2020; Published: 27 May 2020

\begin{abstract}
Novel fluorescent sensors with electron-donating or electron-withdrawing substituents incorporated into a chromophore group based on 2,6-diphenylpyridine were designed and synthesised. The spectroscopic properties of these compounds were studied. Moreover, the positive solvatochromism of 2,6-bis-(4-methylsulphanylphenyl)pyridine $\left(\mathrm{PT}^{\left.-\mathrm{SCH}_{3}\right)}\right.$ in selected solvents was studied by measurement of the absorption and emission spectra and analysed using the Dimroth-Reichardt solvent parameter set. After that, the performance of a series of 2,6-diphenylpyridine derivatives as fluorescent molecular sensors for monitoring free-radical and cationic photopolymerization processes by the Fluorescence Probe Technique (FPT) was studied. As a consequence of this stage of research, the effect of substituents on the sensitivity of the 2,6-diphenylpyridine derivatives as sensors during photopolymerization has been evaluated and discussed. It has been found that compounds containing strong electron-donating substituent $\left(\mathrm{PT}_{-} \mathrm{SCH}_{3}\right)$ slightly shift their fluorescence spectrum during the free-radical polymerization of monomer, which enables the monitoring of the polymerization progress using the fluorescence intensity ratio measured at two different wavelengths as the progress indicator. The position of the fluorescence spectrum of 2,6-diphenylpyridine derivatives with electron-withdrawing substituents is practically insensitive to changes occurring in their environment. Hence, it is recommended to use these compounds with different indicators of the progress of the photopolymerization process based on normalised intensity of fluorescence $\left(\mathrm{I}_{\max } / \mathrm{I}_{0}\right)$. Among the compounds studied, 2,6-bis(4-methylsulphanylphenyl)pyridine $\left(\mathrm{PT}^{-\mathrm{SCH}_{3}}\right)$ turned out to be the best fluorescent sensor for the purpose of monitoring free-radical polymerization by FPT. Consequently, the dual application of the selected 2,6-diphenylpyridine derivatives is proposed: (a) as fluorescent sensors for monitoring the free-radical photopolymerization progress, and (b) as spectroscopic sensors for the determination of efficiencies of the generation of superacids by cationic photoinitiators during the cationic photopolymerization process. Finally, a new method for determining the relative efficiency of the photogeneration of superacids during the photo cleavage of onium salt has been devised and applied for the evaluation of the performance of 2,6-diphenylpyridine derivatives.
\end{abstract}

Keywords: fluorescent molecular sensors; photopolymerization; fluorescence probe technology; cationic photopolymerization; free-radical photopolymerization; superacid generation; $\mathrm{pH}$ sensors 


\section{Introduction}

Common fluorescent molecular sensors play an important role in practically every area of life. Fluorescent chemosensors have been around for about 150 years. Their pioneer is Goppelsröder, who, in 1867, reported the first fluorescent chemosensor for $\mathrm{Al}^{3+}$ [1]. In recent years, a lot of emphasis has been placed on the use of fluorescent sensors, especially in biology [2], biochemistry [3], biotechnology and medicine [4,5], including physiology, pharmacology and environmental sciences [6]. In particular, fluorescent chemosensors for biological and environmental cations [7], anions [8], small neutral molecules [9] and biomacromolecules [10], such as proteins and DNA [11], have been developed alongside rapid advancements in microscopic imaging technology [12]. For example, Schmuck et al. reported a pyrene-based peptide beacon - a fluorescent chemosensor that is intercalated with DNA [11]. The detection of an analyte using a fluorescent chemosensor is usually achieved by one or more common photophysical mechanisms, e.g., chelation-induced enhanced fluorescence (CHEF) [1], intramolecular charge transfer (ICT) [13], photoinduced electron transfer (PET) [14] and induced emission aggregation (AIE) [15].

In recent years, great emphasis has been placed on developing new fluorescent molecular sensors for detecting selected metal ions [3,16-20]. Liu et al. developed a novel 4-amino-1,8-naphthalimidebased fluorescent sensor with iminodiacetic acid as receptor, applied successfully to image $\mathrm{Zn}^{2+}$ in living cells [3]. Song et al. developed a novel fluorescent sensor for $\mathrm{Al}^{3+}$ and $\mathrm{Zn}^{2+}$ based on a new europium complex with a 1,10-phenanthroline ligand [19]. The complex shows high sensitivity and selectivity towards $\mathrm{Al}^{3+}$ and $\mathrm{Zn}^{2+}$ in a methanol solution, which can be attributed to the $\mathrm{Al}^{3+} \mathrm{Zn}^{2+}$ cation instead of $\mathrm{Eu}^{3+}$ in the complex [19]. In turn, Behnam Majidi et al. developed a dual-mode colorimetric-fluorescent sensor for the highly sensitive and selective detection of the $\mathrm{Mg}^{2+}$ ion in aqueous media [20].

Despite the progress made in this area, there are still several problems and challenges [21,22]. In order for these probes to be used in the above-mentioned fields of science, they should meet a number of requirements and respond appropriately to changes in the environment, i.e., changes in viscosity, polarity or $\mathrm{pH}[23,24]$. What is more, if they are to be used in biological sciences, they should be non-toxic and also harmless to the human body. Therefore, new fluorescent sensors for biological applications are being intensively sought. Moreover, the popularity and development of technologies based on the use of fluorescent sensors go hand in hand with the development of spectrofluorometric techniques. This type of technique allows the study of even single sensor molecules and their interaction with other molecular entities under the influence of changes in various physicochemical parameters at the microscopic level. Thus, it distinguishes them from techniques that provide information at the macroscopic level. From a practical point of view, an additional and important feature of fluorescent techniques is the possibility of remote monitoring through the use of fibre optics and laser technologies. Due to the availability of spectroscopic techniques with high detection sensitivity and fast response time, it is possible to obtain accurate information about local physical, structural and chemical parameters of the reaction environment based on, among other things, the characteristics of the emission spectrum [25] (shape, width, intensity), quantum fluorescence performance [26] and sensor lifetimes [27]. In the field of polymer chemistry, techniques based on fluorescence spectroscopy and fluorescent probes are also successfully used. Such probes are compounds that are covalently unrelated to the polymer macromolecule and are able to provide information on the local physical, chemical and structural parameters of the microenvironment. Currently, due to the diversity and heterogeneous and dynamic nature of polymer systems, the big challenge is to study the processes taking place at the molecular and microscopic levels. While most polymeric materials are not fluorescent, these polymers can be tested by placing the appropriate fluorescent probe in them. This solution, in combination with fluorescent techniques (stationary, time-resolved, microscopy), provides non-invasive, non-destructive, in-situ and real-time studies of the structure and dynamics of the processes occurring in polymers. These are compounds that respond to changes in the environment. With regard to their application in the field of polymers [28], they are used in studies of the physicochemistry of polymers [8], as well as the 
kinetics of polymerization processes [26]. These probes can generally be grouped into several types, based on the following mechanisms: TICT (Twisted Intermolecular Charge Transfer) effect [29] (e.g., 4-dimethylamino benzonitrile and 4-dimethylaminobenzoic acid ethyl ester) [30]; sensors based on the ICT (Intermolecular Charge Transfer) effect [31,32], exciplex formation (e.g., pyrene); and changes in phosphorescence characteristics instead of fluorescence (i.e., phosphorescent probes). Fluorogenic probes are also known, which do not fluoresce in an unbound form, but strongly fluoresce after incorporation into the polymer structure (e.g., 1-phenyl-4-(4-cyano-1-naphthylmethylene) piperidine, commonly referred to as "Fluoroprobe") [33]. In addition, organic salt type probes (e.g., stilbazolium salts) [34] can also be distinguished, which show intermolecular excited electron transfer from the dimethylamino group to the pyridine or benzothiazole ring, but, unlike ICT or TICT probes, electron transfer does not cause a significant change in the dipole moment of excited states compared to the dipole moment these probes have in their ground state.

Currently, we have many methods for continuously monitoring the progress of photopolymerization. These allow monitoring of polymerization in real-time (on-line) upon irradiation to light. One of the famous and commonly used methods belonging to this group is isothermal differential scanning calorimetry (photo-DSC) [35-37]. Therefore, this method is unsuitable for determining the conversion of high-speed processes such as photopolymerization. Fourier-transform infrared spectroscopy in real-time (real-time-FT-IR) [38,39] is also a frequently used method, enabling the monitoring of the disappearance of absorbance bands at wavenumbers corresponding to the bands of a specific functional group. This method, due to its short response time, can be used to determine the conversion rates of photopolymerization. However, FT-IR also has limitations, such as sensitivity to light, humidity, and oxygen, which cause the results to be falsified. Therefore, fluorescence spectroscopy is gaining popularity.

The basis of this technique, called Fluorescence Probe Technology (FPT), is to measure changes in the probe's emission spectrum as the environment changes [40]. During the photopolymerization process, due to the increase in system viscosity, there may be changes in the quantum efficiency of probe fluorescence, the location of the maximum intensity of the emission spectrum, fluorescence intensity and fluorescence polarization [41]. In turn, commonly used parameters to monitor the progress of the photopolymerization process in Fluorescence Probe Technology includes the so-called parameter of the ratio of fluorescence intensity $(R)$ measured at two wavelengths located on both sides of the maximum fluorescence spectrum [42] and the parameter $\mathrm{I}_{\max } / \mathrm{I}_{0}$ defined as the normalised fluorescence intensity measured at the maximum emission spectrum [43]. Parameter R illustrates the change in the shift of emission spectra during irradiation of the system. Typically, the ratio $\mathrm{R}$ is determined by dividing the intensity at a smaller wavelength $\left(\mathrm{I}_{1}\right)$ by the intensity at a larger wavelength $\left(\mathrm{I}_{2}\right)$. Fluorescence Probe Technology can be fruitfully deployed to investigate various processes and phenomena in polymer science, such as different types of polymerization processes [44-48], (including cross-linking and gel formation), irreversible film formation by physical interpenetration and the diffusion of polymer chains across interfaces, phase separation, and reversible transitions, such as glass transitions [43].

As part of this work, new 2,6-diphenylpyridines were developed as sensors for the determination of efficiencies of superacid generation by cationic photoinitiators using Fluorescence Probe Technology. Unlike the complicated structure of the pyridine terphenyls presented in a previous article [49], the pyridine terphenyls presented in this article are colourless in visible light, which is extremely important from an industrial point of view. Commercially available photoinitiators-iodonium salts, such as diphenyliodonium hexafluorophosphate (HIP) — and the commercially available monomer triethylene glycol divinyl ether (TEGDVE) were used for the cationic photopolymerization process. As a result of the cationic photopolymerization process involving photoinitiators, the emission spectrum was shifted towards longer wavelengths, which is directly related to the release of acid originating from the photoinitiator. The rate of acid evolution from the HIP photoinitiator was compared depending on the chemical structure of the sensors, i.e., from the nature of the substituent based on its electron-donating or electron-withdrawing character. Moreover, the impact of environmental $\mathrm{pH}$ changes and polarity 
on the emission spectra of selected 2,6-diphenylpyridine compounds was investigated. Finally, 2,6-diphenyl pyridine derivatives were also investigated as fluorescent sensors for monitoring the kinetics of the free-radical photopolymerization processes of the model trimethylpropane triacrylate monomer (TMPTA) as a process in which strong protic acid is not generated.

\section{Materials and Methods}

Eight 2,6-diphenyl pyridine derivatives, differentiated in terms of attached substituents, were tested as molecular fluorescent sensors. These were 2,6-diphenylpyridine (PT-H), 2,6-bis(4methoxyphenyl)pyridine $\left(\mathrm{PT}-\mathrm{OCH}_{3}\right)$, 2,6-bis(4-methylsulphanylphenyl)pyridine $\left(\mathrm{PT}-\mathrm{SCH}_{3}\right), 2,6-\mathrm{bis}$ (p-tolyl)pyridine (PT-CH $\mathrm{CH}_{3}$, 2,6-bis(4-fluorophenyl)pyridine (PT-F), 2,6-bis(4-cyanophenyl)pyridine (PT-CN), 2,6-bis[4-(trifluoromethyl)phenyl]pyridine (PT- $\mathrm{CF}_{3}$ ) and 2,6-bis(4-methylsulphonylphenyl) pyridine (PT-SO $\mathrm{CH}_{3}$ ). The structures of 2,6-diphenyl pyridine derivatives are shown in Scheme 1. The synthesis pathways of the analysed derivatives are described in detail in the Supplementary Information, which also includes the results of NMR (Figures S1-S16), LC-MS analyses and visualization of the fluorescence of powders of these compounds (Figure S17).<smiles>c1ccc(-c2cccc(-c3ccccc3)n2)cc1</smiles>

PT-H<smiles>Fc1ccc(-c2cccc(-c3ccc(F)cc3)n2)cc1</smiles>

PT-F<smiles>COc1ccc(-c2cccc(-c3ccc(OC)cc3)n2)cc1</smiles>

PT-OCH 3<smiles>N#Cc1ccc(-c2cccc(-c3ccc(C#N)cc3)n2)cc1</smiles>

PT-CN<smiles>CSc1ccc(-c2cccc(-c3ccc(SC)cc3)n2)cc1</smiles>

PT-SCH 3<smiles>FC(F)(F)c1ccc(-c2cccc(-c3ccc(C(F)(F)F)cc3)n2)cc1</smiles>

$\mathrm{PT}^{-\mathrm{CF}_{3}}$<smiles>Cc1ccc(-c2cccc(-c3ccc(C)cc3)n2)cc1</smiles>

$\mathrm{PT}-\mathrm{CH}_{3}$<smiles>CS(=O)(=O)c1ccc(-c2cccc(-c3ccc(S(C)(=O)=O)cc3)n2)cc1</smiles>

PT-SO $\mathrm{CH}_{3}$

Scheme 1. Structures of molecular fluorescent sensors.

For the cationic photopolymerization, triethylene glycol divinyl ether (TEGDVE, from Sigma Aldrich) as a model vinyl ether monomer and diphenyliodonium hexafluorophosphate (HIP, from Alfa Aesar) as a photoinitiator were used. For the free-radical photopolymerization, ttrimethylolpropane triacrylate (TMPTA, from Sigma Aldrich) was used as a methacrylate monomer and 2,2-dimethoxy-2-phenylacetophenone (DMPA, from Sigma Aldrich) as a free-radical photoinitiator. The structures of monomers and model photoinitiators are shown in Scheme 2.

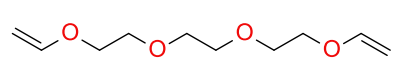

TEGDVE

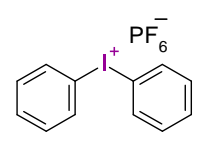

HIP<smiles>COC(OC)(OC)c1ccccc1</smiles>

DMPA

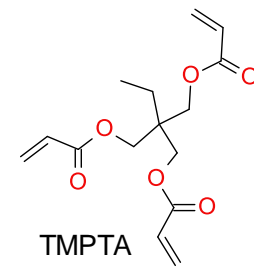

Scheme 2. Chemical structures of monomers and photoinitiators.

\subsection{Spectral Measurements}

The absorption and fluorescence spectra of 2,6-diphenylpyridine derivatives were measured in acetonitrile (from Sigma Aldrich), using the SilverNova spectrometer (StellarNet, Inc., Tampa, FL, USA), in combination with a broadband tungsten-deuterium UV-Vis light source (from StellarNet, Inc., Tampa, FL, USA) and a quartz cuvette with a $1.0-\mathrm{cm}$ optical path. Next, the absorbance data were converted into extinction coefficients, expressed in units $\left[\mathrm{dm}^{3} \mathrm{~mol}^{-1} \mathrm{~cm}^{-1}\right]$. The absorption 
and fluorescence measurements of 2,6-diphenylpyridine were measured in acetonitrile at $25{ }^{\circ} \mathrm{C}$ using 10 -mm-thick quartz cells. The fibre-optic cable used for the transmission of light from the measurement site to the spectrometer was made of PMMA optical fibre with a 2-mm core (from Fibrochem, Poland).

The emissions of the analysed compound 2,6-bis(4-methoxyphenyl)pyridine (PT-OCH$)$ in buffers at different $\mathrm{pHs}$ were recorded using the spectrofluorometer FluoroMAX 4Plus with MicroMax Plus (from Horiba, Kioto, Japan), which was used in standard 96-well plates (from Thermo Scientific).

Fluorescence emission and excitation spectra in different solvents (polarity experiments) were recorded using the Quanta Master ${ }^{\mathrm{TM}} 40$ spectrofluorometer (from Photon Technology International (PTI), currently a part of Horiba, Kioto, Japan) at varied excitation and observation wavelengths in the range of $200-800 \mathrm{~nm}$.

\subsection{Steady State Photolysis}

Steady state photolysis was carried out using the same spectrometer as for the absorption studies. The measurement consisted in the following: cuvettes with the 2,6-diphenylpyridine derivatives in acetonitrile were irradiated by UV-LED $320 \mathrm{~nm}$ (UVTOP315-BL-TO39, Roithner Laser Technik GmbH, Wien, Austria) emitting light with wavelength at $\lambda_{\max }=320 \mathrm{~nm}\left(\sim 1 \mathrm{~mW} / \mathrm{cm}^{2}\right.$, current $\left.20 \mathrm{~mA}\right)$, and by UV-LED-300 M300L4 (from Thorlabs Inc., Tampa, FL, USA) emitting light with wavelength at $\lambda_{\text {max }}=300 \mathrm{~nm}\left(\sim 26 \mathrm{~mW} / \mathrm{cm}^{2}\right.$, current $\left.350 \mathrm{~mA}\right)$ for $20 \mathrm{~min}$. The source of light was powered by a DC2200 regulated power supply (from Thorlabs Inc., Tampa, FL, USA). The UV-Vis spectra were recorded with the UV/Vis deuterium-halogen light source SL5 (from StellarNet, Inc., Tampa, FL, USA). The photolysis of 2,6-bis(4-methoxyphenyl)pyridine $\left(\mathrm{PT}-\mathrm{OCH}_{3}\right)$ derivatives in the presence of different amounts of iodonium salt (HIP) was determined with the same parameters over 20 min when exposed to UV-LED $320 \mathrm{~nm}$ with a maximum emission of $320 \mathrm{~nm}$.

\subsection{Preparation of Samples for Monitoring the Photopolymerization Processes by FPT}

Samples for the FPT photopolymerization studies were prepared in dark amber glass vials in a dark room by dissolving the photoinitiator diphenyliodonium hexafluorophosphate and each 2,6-diphenylpyridine derivative compound in the monomer in such proportions as to obtain a concentration of $1.0 \%$ by weight photoinitiator and $0.1 \%$ by weight sensor. The finished samples in the glass vials with the composition were wrapped in aluminium foil and stored in a dark place to protect against accidental exposure to daylight. Prior to the measurement, two drops of the composition were placed at the centre of the microscope slide $(75 \mathrm{~mm} \times 25 \mathrm{~mm} \times 1 \mathrm{~mm}$, from Thermo Scientific), equipped with two 0.09 -mm thick spacers placed on the sides of the slide. The slide was covered with a second microscope slide to create a sandwich structure. In order to maintain the constant thickness of the composition, the whole was compressed on both sides by clips. The sample prepared in this way was placed into a measuring chamber. Prior to the measurement, the sample was thermostated for a few minutes at the set temperature. For the preparation of thin-layer samples, essential microscope slides with dimensions of $26 \mathrm{~mm} \times 76 \mathrm{~mm} \times 1 \mathrm{~mm}$ from Menzel-Glaser, in accordance with ISO 8037/I, were used. A uniform type of self-adhesive paper spacer was used for the spacers.

\subsection{Monitoring Fluorescence Changes during Photopolymerization}

The apparatus of the Fluorescence Probe Technology was composed of a sample compartment, equipped with a miniature CCD spectrometer (SilverNova from StellarNet, Inc., Tampa, FL, USA), interfaced to a microcomputer for data acquisition, and a UV-LED emitting at wavelength of $\lambda_{\max }=320 \mathrm{~nm}$ (UVTOP315-BL-TO39, Roithner LaserTechnik GmbH, Vienna, Austria) incorporated into the sensor head. FPT photopolymerization reaction studies were carried out under controlled, thermostatic conditions. For this purpose, a measuring chamber, impermeable to daylight, was specially designed and equipped with a thermostatic head, with high accuracy $\left( \pm 0.1^{\circ} \mathrm{C}\right)$, which maintained the set temperature inside the chamber using an electronically controlled Peltier cell as a heat pump. Depending on the temperature difference between the inside of the chamber and the surroundings, the 
cell carried heat outside or inside the chamber. The measuring head, chamber bottom and thermostatic head were made of aluminium, and the walls were made of a piece of 4 -inch stainless steel pipe with an external diameter of $101.6 \mathrm{~mm}$ and a wall thickness of $2 \mathrm{~mm}$. The interior of the chamber was additionally covered with a layer of Teflon, which served as a heat insulator. A measuring head with a UV-LED was mounted at the bottom of the chamber, where a sample of the composition directly adhered, whose spot (about $5 \mathrm{~mm}$ in diameter) illuminated the tested thin-film sample. A PMMA optical cable with a core diameter of $2 \mathrm{~mm}$ was used to transfer fluorescent light from the measurement site to the spectrometer. The UV LED was powered by a 20-mA direct current from a stabilised current source. The main advantage of this measuring chamber was the high intensity of the excitation light from the same type of UV-LEDs and the small scattering of the excitation light compared to previous measuring systems [22]. This was due to the elimination of one of the fibre-optic cables and the incorporation of the UV-LED directly into the chamber head. The appearance of the apparatus for monitoring the kinetics of photopolymerization processes was similar to those described earlier [50], albeit modernised by means of a thermostat system that guaranteed the stability of environmental conditions during photopolymerization. Free-radical and cationic photopolymerization processes were carried out at an ambient temperature of $25^{\circ} \mathrm{C}$ using the ITC4020 thermostat (from Thorlabs Inc., Newton, NJ, USA). A photograph of the measurement system is shown in Figure 1.

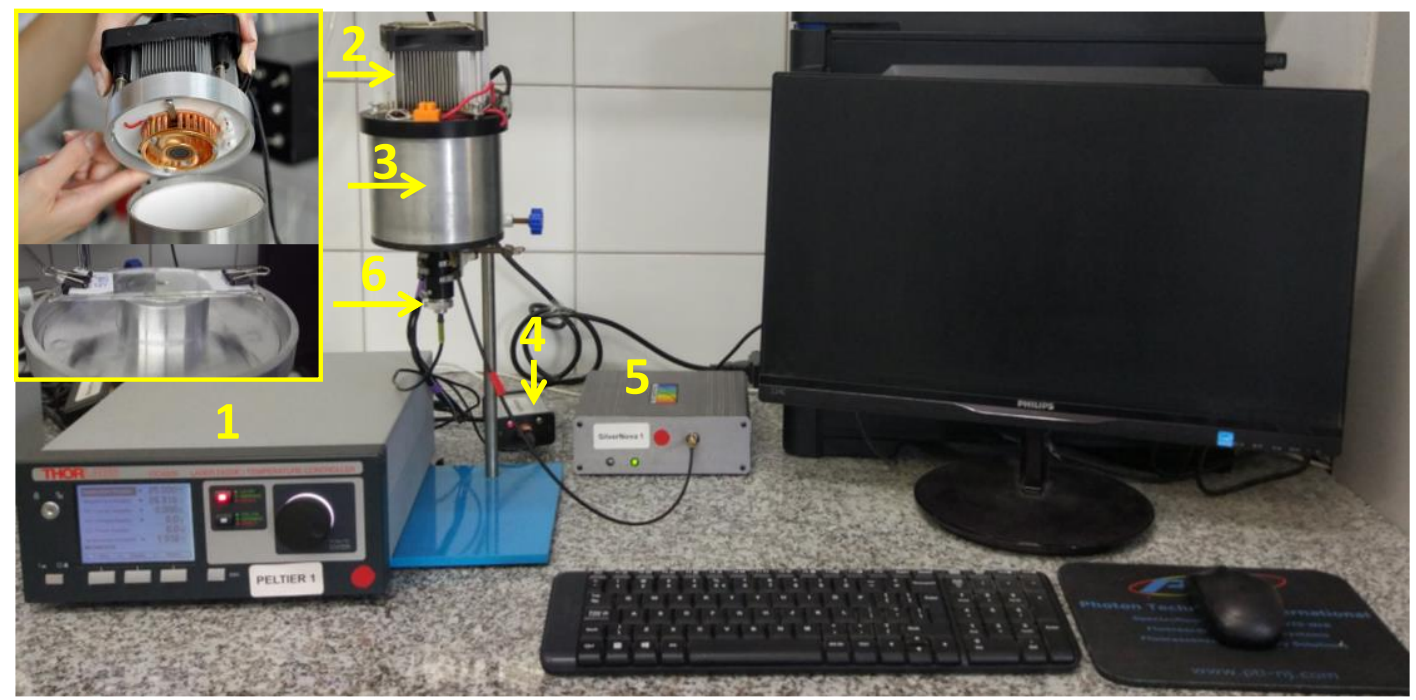

Figure 1. A stationary cure monitoring system was composed of a microcomputer-controlled miniature spectrometer (EPP2000C from StellarNet, Inc., Tampa, FL, USA): 1-thermostat (Thorlabs, Inc., Newton, NJ, USA), 2-Peltier cell with heatsink, 3-measuring chamber, 4-power supply, 5-spectrometer (StellarNet, Inc., Tampa, FL, USA), 6-UV-LED diode.

\section{Results and Discussion}

\subsection{Spectroscopic Properties of 2,6-Diphenylpyridine Derivatives}

The most important parameters describing the spectroscopic properties of molecular probes are absorbance, the molar extinction coefficient, fluorescence and Stokes shift. The analysis of the electronic absorption spectra of 2,6-diphenylpyridine derivatives clearly indicates the presence of two main bands, whose maxima are located in the UV-C range between 220-280 nm for the first band, and in the UV-B range above $300 \mathrm{~nm}$ for the second band (Figure 2, Table 1). The shortest wavelength bands are attributed to the $\pi \rightarrow \pi^{*}$ transitions, whereas the long wavelength bands, are attributed to the $\mathrm{n} \rightarrow \pi^{*}$ transitions. 


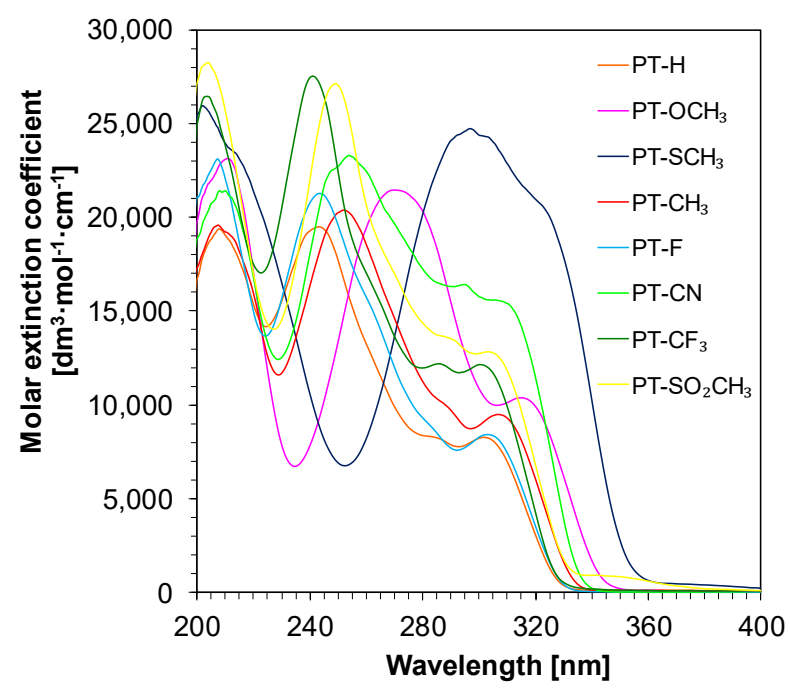

Figure 2. UV-visible absorption spectra of the 2,6-diphenylpyridine derivatives in acetonitrile.

Table 1. Spectral characteristics of the 2,6-diphenylpyridine derivatives.

\begin{tabular}{|c|c|c|c|c|c|c|}
\hline \multirow[b]{2}{*}{ Acronym } & \multicolumn{6}{|c|}{ Absorption Characteristics } \\
\hline & 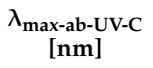 & $\begin{array}{c}\varepsilon_{\max } \\
{\left[\mathrm{dm}^{3} \cdot \mathrm{mol}^{-1} \cdot \mathrm{cm}^{-1}\right]}\end{array}$ & $\underset{[\mathrm{nm}]}{\lambda_{\text {max-ab-UV-B }}}$ & $\begin{array}{c}\varepsilon_{\max -U V-B} \\
{\left[\mathrm{dm}^{3} \cdot \mathrm{mol}^{-1} \cdot \mathrm{cm}^{-1}\right]}\end{array}$ & $\begin{array}{c}\varepsilon_{300} \\
{\left[\mathrm{dm}^{3} \cdot \mathrm{mol}^{-1} \cdot \mathrm{cm}^{-1}\right]}\end{array}$ & {$\left[\begin{array}{c}\mathcal{E}_{320} \\
{\left[\mathrm{dm}^{3} \cdot \mathrm{mol}^{-1} \cdot \mathrm{cm}^{1}\right]}\end{array}\right.$} \\
\hline PT-H & 243 & 19,490 & 302 & 8269 & 8230 & 3066 \\
\hline $\mathrm{PT}-\mathrm{OCH}_{3}$ & 270 & 21,454 & 314 & 10,377 & 10,802 & 9913 \\
\hline PT-SCH 3 & 292 & 24,336 & 317 & 21,382 & 24,367 & 20,962 \\
\hline $\mathrm{PT}-\mathrm{CH}_{3}$ & 252 & 20,381 & 307 & 9488 & 8925 & 6043 \\
\hline PT-F & 244 & 21,272 & 303 & 8417 & 8297 & 3528 \\
\hline PT-CN & 254 & 23,302 & 306 & 15,590 & 15,755 & 11,465 \\
\hline $\mathrm{PT}-\mathrm{CF}_{3}$ & 241 & 27,526 & 300 & 12,148 & 12,148 & 4262 \\
\hline PT- $\mathrm{SO}_{2} \mathrm{CH}_{3}$ & 249 & 27,126 & 303 & 12,829 & 12,743 & 6805 \\
\hline
\end{tabular}

$\lambda_{\text {max-ab-UV-C }}$-position of absorption maximum for the short-wavelength band [nm]; $\varepsilon_{\max }$-molar extinction coefficient measured at $\lambda_{\text {max-ab-UV-C }}\left[\mathrm{dm}^{3} \cdot \mathrm{mol}^{-1} \cdot \mathrm{cm}^{-1}\right] ; \lambda_{\text {max-ab-UV-B }}$-position of absorption maximum for the longer-wavelength band [nm]; $\varepsilon_{\text {max-UV-B }}$-molar extinction coefficient measured at $\lambda_{\text {max-ab-UV-B }}\left[\mathrm{dm}^{3} \cdot \mathrm{mol}^{-1} \cdot \mathrm{cm}^{-1}\right]$; $\varepsilon_{300}$-molar extinction coefficient measured at $300 \mathrm{~nm}\left[\mathrm{dm}^{3} \cdot \mathrm{mol}^{-1} \cdot \mathrm{cm}^{-1}\right] ; \varepsilon_{320}$-molar extinction coefficient measured at $320 \mathrm{~nm}\left[\mathrm{dm}^{3} \cdot \mathrm{mol}^{-1} \cdot \mathrm{cm}^{-1}\right]$.

In order to determine the Stokes shift, the emission and excitation spectra of the investigated compounds were measured. The calculated Stokes shift ranged from $2116 \mathrm{~cm}^{-1}$ for 2,6-bis (4-cyanophenyl)pyridine (PT-CN), to $2963 \mathrm{~cm}^{-1}$ for 2,6-bis(4-methylsulphonylphenyl)pyridine (PT-SO $\mathrm{CH}_{3}$ ). In addition, compounds with electron-donating substituents, i.e., $\mathrm{SCH}_{3}, \mathrm{OCH}_{3}$ and $\mathrm{CH}_{3}$, show a bathochromic shift of both excitation and emission spectra in the direction of longer waves compared to 2,6-diphenylpyridine (PT-H) (Figure 3). For example, the wavelength for the maximum intensity of the emission spectrum for the 2,6-bis-(4-methylsulphanylphenyl)pyridine $\left(\mathrm{PT}^{-} \mathrm{SCH}_{3}\right)$ is located at $374 \mathrm{~nm}$, so it is $33 \mathrm{~nm}$ higher than the wavelength for the maximum intensity of the emission spectrum for the basic compound 2,6-diphenylpyridine (PT-H) with maximum emission located at $341 \mathrm{~nm}$. All spectrum data are presented in Table 2 (the visualization of the fluorescence of the pyridines in solution Figure S18). 


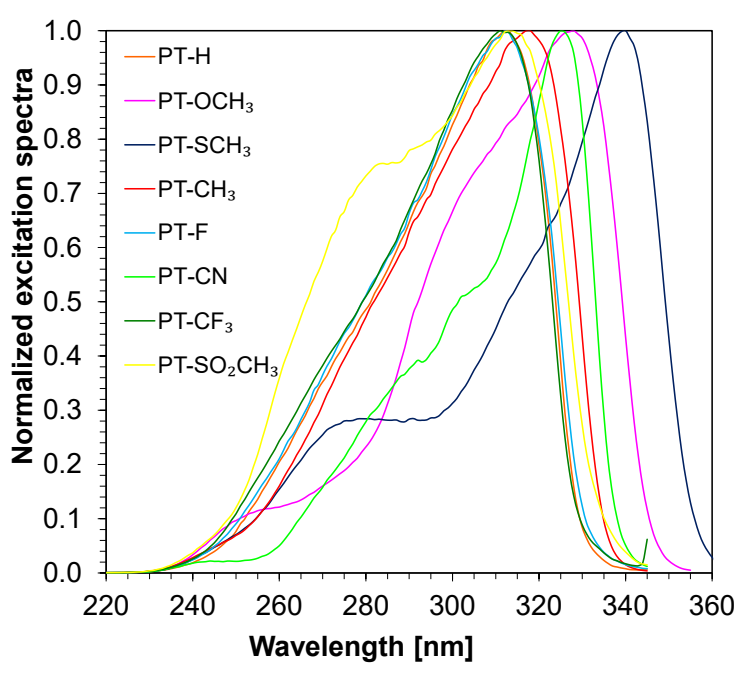

(a)

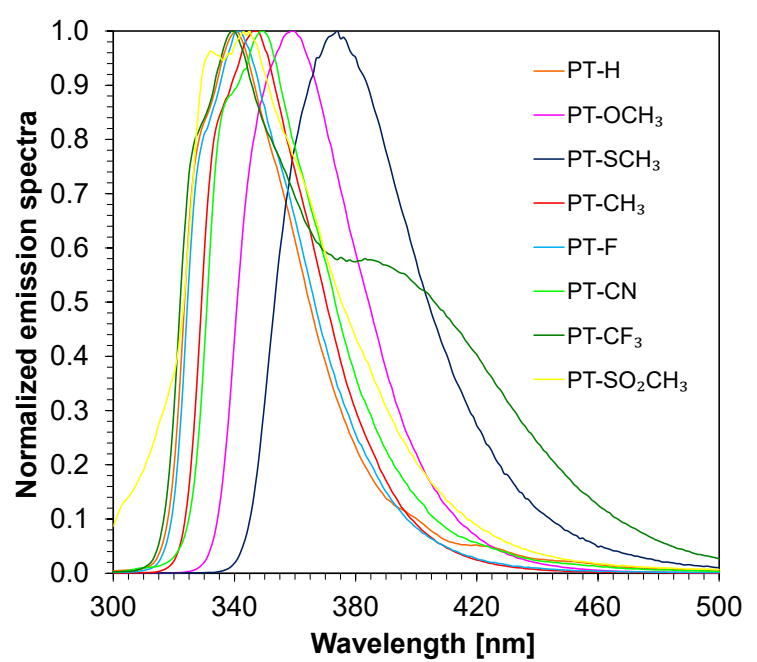

(b)

Figure 3. (a) Normalized excitation spectra of the 2,6-diphenylpyridine derivatives in acetonitrile; (b) Normalized emission spectra of the 2,6-diphenylpyridine derivatives in acetonitrile; $\lambda_{\mathrm{ex}}=290 \mathrm{~nm}$ is the excitation wavelength, used to obtain emission spectra.

Table 2. Spectral characteristics of the 2,6-diphenylpyridine derivatives in acetonitrile.

\begin{tabular}{|c|c|c|c|c|}
\hline \multirow[b]{2}{*}{ Acronym } & \multicolumn{2}{|c|}{ Excitation } & \multirow{2}{*}{$\begin{array}{c}\text { Emission at } \lambda=290 \mathrm{~nm} * * \\
\lambda_{\text {max-em }} \\
{[\mathrm{nm}]}\end{array}$} & \multirow{2}{*}{$\begin{array}{c}\Delta v \\
\text { Stokes Shift } \\
{\left[\mathrm{cm}^{-1}\right]}\end{array}$} \\
\hline & $\begin{array}{c}\text { at }^{*} \\
{[\mathrm{~nm}]}\end{array}$ & $\begin{array}{c}\lambda_{\text {max-ex }} \\
{[\mathrm{nm}]}\end{array}$ & & \\
\hline PT-H & 350 & 313 & 341 & 2623 \\
\hline $\mathrm{PT}^{\mathrm{O}} \mathrm{OCH}_{3}$ & 360 & 328 & 359 & 2633 \\
\hline $\mathrm{PT}_{-} \mathrm{SCH}_{3}$ & 370 & 340 & 374 & 2674 \\
\hline $\mathrm{PT}^{-\mathrm{CH}_{3}}$ & 350 & 318 & 346 & 2545 \\
\hline PT-F & 350 & 312 & 342 & 2812 \\
\hline PT-CN & 350 & 325 & 349 & 2116 \\
\hline $\mathrm{PT}-\mathrm{CF}_{3}$ & 350 & 311 & 340 & 2743 \\
\hline PT-SO ${ }_{2} \mathrm{CH}_{3}$ & 350 & 313 & 345 & 2963 \\
\hline
\end{tabular}

$\lambda_{\max -e x}$-wavelength for the maximum intensity of the excitation spectrum; $\lambda_{\max -\mathrm{em}}$-wavelengths for the maximum intensity of the emission spectrum; * wavelength used to obtain excitation spectra; ${ }^{* *} 290 \mathrm{~nm}$ is the excitation wavelength, used to obtain emission spectra.

Due to the fact that photopolymerization processes are very fast, they require continuous exposure to light of a certain length; therefore, an analysis of the photostability of the actual derivatives was undertaken. The stability of the 2,6-diphenylpyridine derivatives was tested by measuring the absorbance response during $20 \mathrm{~min}$ in acetonitrile under irradiation by UV-LEDs with maximum emission at $300 \mathrm{~nm}$ (intensity of irradiation $26 \mathrm{~mW} / \mathrm{cm}^{2}$ ) and at $320 \mathrm{~nm}$ (intensity of irradiation $1 \mathrm{~mW} / \mathrm{cm}^{2}$ ) (Figure 4). The absorption characteristics were continuously monitored and recorded at set time intervals across the entire spectrum. The results indicated that the 2,6-diphenylpyridine derivatives could be used as sensors because of their good stability with no solids precipitated during irradiation. Thus, the probe can be used to monitor kinetic parameters during photopolymerization processes in real time. Other spectra are presented in the Supplementary Information (Figures S19-S31). 


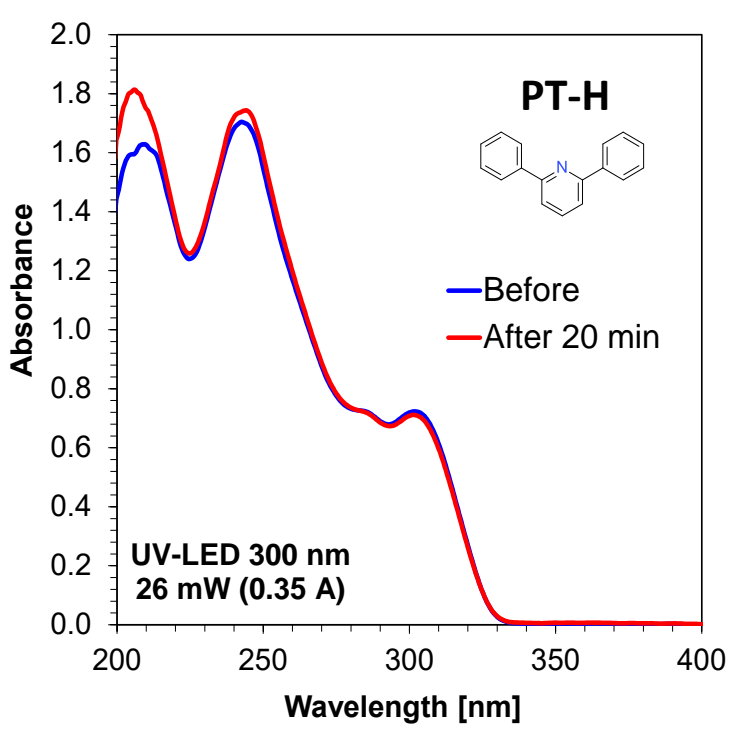

(a)

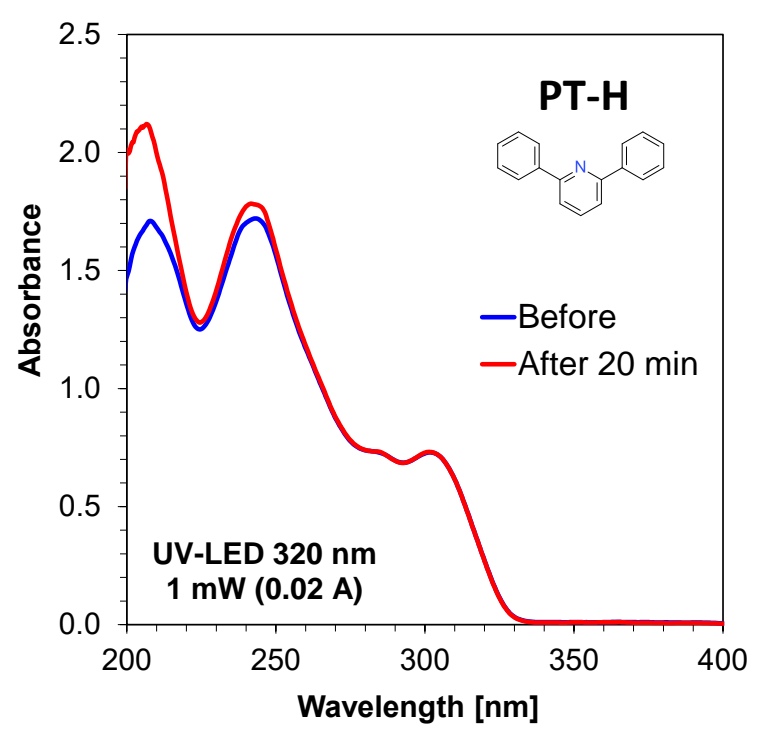

(b)

Figure 4. Photolysis of 2,6-diphenylpyridine (PT-H, concentration: $\left.8.83 \times 10^{-5}\left[\mathrm{~mol} / \mathrm{dm}^{3}\right]\right)$ in ACN during $20 \mathrm{~min}$ : (a) under $300 \mathrm{~nm}\left(26 \mathrm{~mW} / \mathrm{cm}^{2}\right)$; (b) under $320 \mathrm{~nm}\left(1 \mathrm{~mW} / \mathrm{cm}^{2}\right)$.

Due to the fact that FPT technology is based on the analysis of changes in the fluorescence sensor emission spectra during the photopolymerization process, it was decided to proceed to the next research stage related to the analysis of the sensitivity of the developed derivatives to changes in environmental polarity. For this purpose, two different types of 2,6-diphenylpyridine derivatives were selected in order to study the effect of changes in solvent polarity on their emission and excitation spectra. The first investigated sensor was 2,6-bis(4-methylsulphanylphenyl)pyridine (PT-SCH 3$)$, which has an electron-donating substituent in the diphenylpyridine framework. The second derivative was 2,6-bis(4-cyanophenyl)pyridine (PT-CN) with an electron-withdrawing substituent in its structure. The figures of the emission and excitation spectra of the analysed compounds are presented in Figure 5. In both cases, during changes in the polarities of the solvents, no significant changes of the position of the maximum in their excitation spectra were observed. Nevertheless, this was not the case when the emission spectra of the PT-SCH${ }_{3}$ compound were analysed depending on solvent polarity. Examining the data summarised in Table 3 and Figure 5, it was seen that the maximum of fluorescence only changed for the $\mathrm{PT}-\mathrm{SCH}_{3}$ derivative. The position of maximum fluorescence intensity ranged from $361 \mathrm{~nm}$ to $387 \mathrm{~nm}$ and highly depended on the polarity of the solvents. This compound, which has an electron-donating substituent into 2,6-diphenylpyridine moiety, exhibits a shift in emission spectra as solvent polarity increases.

Based on the obtained spectroscopic data, it can be seen that both molecules differ in the amount of dipole moment excited. More specifically, the derivative of $\mathrm{PT}_{-} \mathrm{SCH}_{3}$ shows a significant change in dipole moment at the moment of electron excitation, while PT-CN shows only a small change. Since the polar solvent interacts more strongly with the molecule, and if there is a rapid change in its dipole moment, for example, during excitation, the solvent molecules remain not optimally aligned to the $\mathrm{PT}-\mathrm{SCH}_{3}$ molecule. Solvent relaxation reduces the energy of the excited state (stabilizes it), and, hence, the observation of such a significant change in the photons' energy is emitted by PT-SCH $\mathrm{H}_{3}$ in polar solvents. Therefore, the observed differences between PT-SCH $\mathrm{H}_{3}$ and PT-CN result from different dipole moments during the excitation of these molecules. $\mathrm{PT}_{-} \mathrm{SCH}_{3}$ is generally more polarized than the other derivatives; therefore, the transitions between its states have the least energy. 


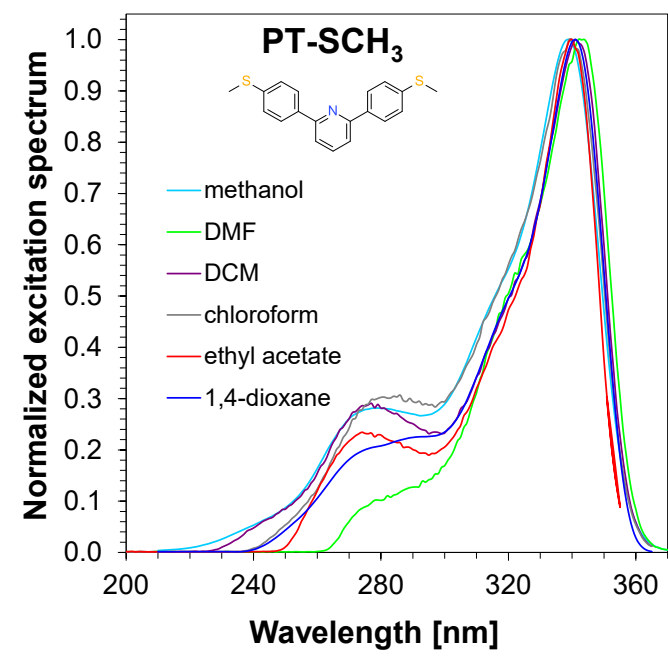

(a)

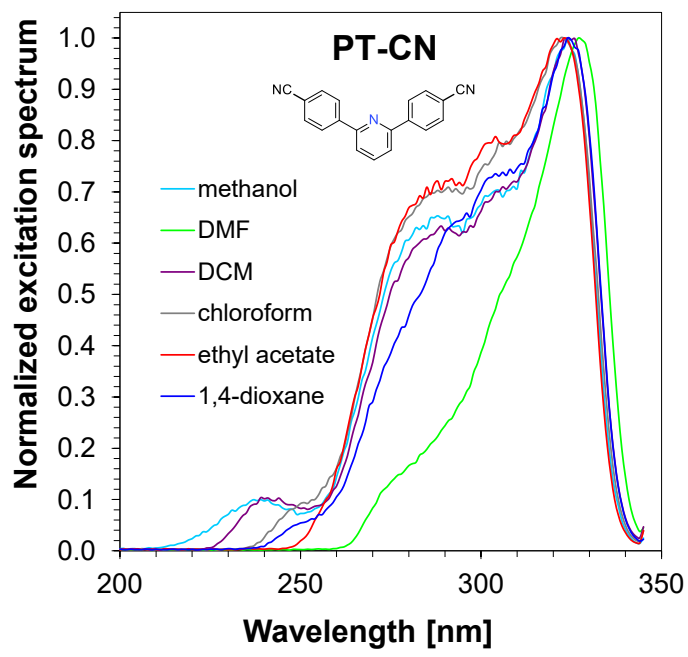

(c)

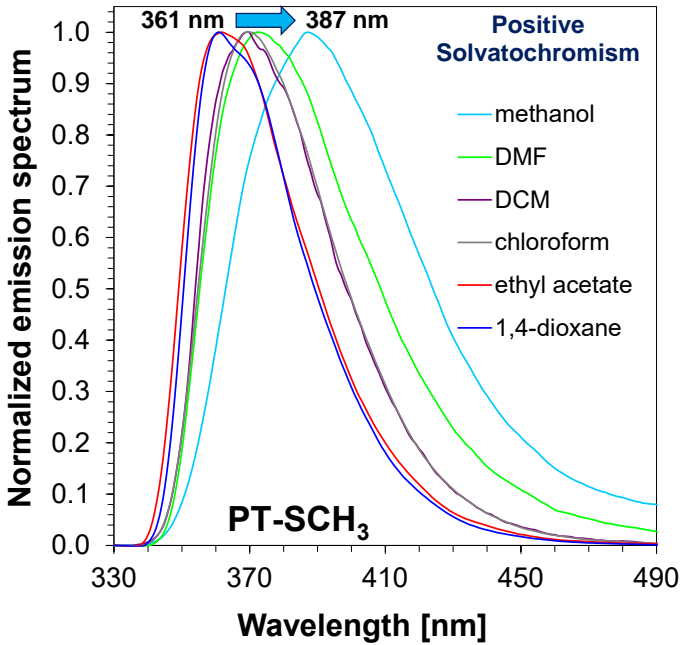

(b)

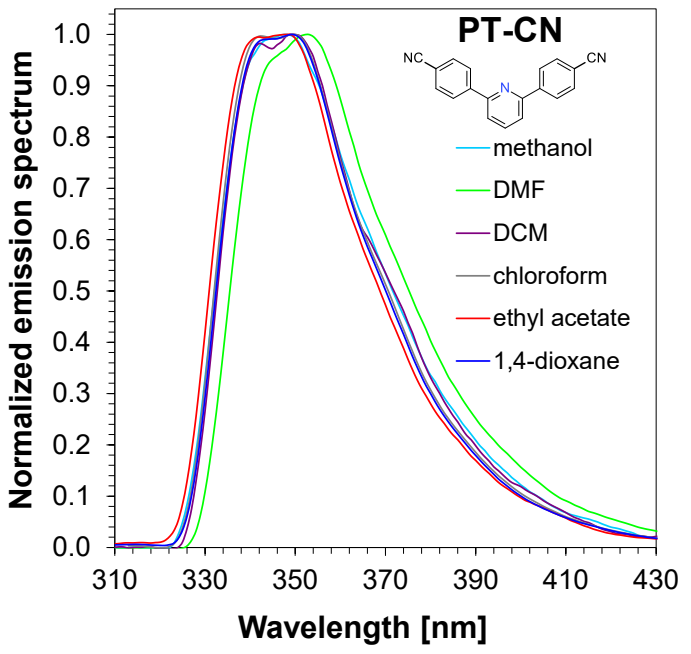

(d)

Figure 5. Spectroscopic properties of diphenylpyridine derivatives in solvents of different polarity: (a) normalised excitation spectrum for 2,6-bis(4-methylsulphanylphenyl)pyridine $\left(\mathrm{PT}^{-} \mathrm{SCH}_{3}\right)$; (b) normalised emission spectrum for 2,6-bis(4-methylsulphanylphenyl)pyridine $\left(\mathrm{PT}_{-} \mathrm{SCH}_{3}\right)$; (c) normalised excitation spectrum for 2,6-bis(4-cyanophenyl)pyridine (PT-CN); (d) normalised emission spectrum for 2,6-bis(4-cyanophenyl)pyridine (PT-CN).

Table 3. Summarised data on excitation and emission spectra of $\mathrm{PT}_{-} \mathrm{SCH}_{3}$ and $\mathrm{PT}-\mathrm{CN}$ compounds.

\begin{tabular}{cccccc}
\hline & & \multicolumn{2}{c}{ PT-SCH $_{3}$} & \multicolumn{2}{c}{ PT-CN } \\
\cline { 3 - 6 } Solvent & $E_{N}^{T}$ & $\begin{array}{c}\text { Excitation } \\
\text { Spectrum } \\
\lambda_{\text {max-ex }}[\mathbf{n m}]\end{array}$ & $\begin{array}{c}\text { Emission } \\
\text { Spectrum } \\
\lambda_{\text {max-Fl }}[\mathbf{n m}]\end{array}$ & $\begin{array}{c}\text { Excitation } \\
\text { Spectrum } \\
\lambda_{\text {max-ex }}[\mathbf{n m}]\end{array}$ & $\begin{array}{c}\text { Emission } \\
\text { Spectrum } \\
\lambda_{\text {max-F1 }}[\mathbf{n m}]\end{array}$ \\
\hline methanol & 0.792 & 339 & 387 & 324 & 347 \\
DMF (dimethylformamide) & 0.386 & 342 & 372 & 327 & 352 \\
DCM (dichloromethane) & 0.309 & 341 & 369 & 324 & 349 \\
chloroform & 0.259 & 339 & 369 & 322 & 349 \\
ethyl acetate & 0.228 & 340 & 362 & 323 & 348 \\
1,4-dioxane & 0.164 & 341 & 361 & 324 & 349 \\
\hline
\end{tabular}

$E_{N}^{T}$-scale of polarity [51]; $\lambda_{\max -\mathrm{ex}}$-wavelength for the maximum intensity of the excitation spectrum [nm]; $\lambda_{\text {max-Fl }}$-wavelengths for the maximum intensity of the emission spectrum [nm]. 
Therefore, the correlation between solvent polarity in the Dimroth-Reichardt solvent scale $\mathrm{E}_{\mathrm{T}}(30)$ and maximum fluorescence wavelength for 2,6-bis(4-methylsulphanylphenyl)pyridine was examined, and a linear relationship with a good correlation coefficient $\left(R^{2}\right)$ was obtained $(R=0.96)$ (Figure 6$)$. The positive slope of the linear correlations between the maxima of fluorescence wavelength positions and solvent polarity indicates that the sensor exhibits positive solvatochromism. Moreover, larger slope values in the case of fluorescence data than in the case of absorption data indicate higher polarity of the excited state of the probe than the polarity of the ground state. Based on these measurements, we can confidently predict that the $\mathrm{PT}-\mathrm{SCH}_{3}$ compound will be sensitive to changes of polarity during the process of photopolymerization. This is due to the fact that, as the photopolymerization of the monomer progresses, the polarity of the system decreases, because the monomer double bonds, which are more polarised, are converted into single bonds in the polymer, which are less polarised. Thus, the polarity of the environment is reduced. In contrast, 2,6-bis(4-cyanophenyl)pyridine (PT-CN), with an electron-withdrawing substituent in the diphenylpyridine framework, is not sensitive to changes in polarity and is not suitable as a sensor sensitive to changes in polarity (Figures 5 and 6).

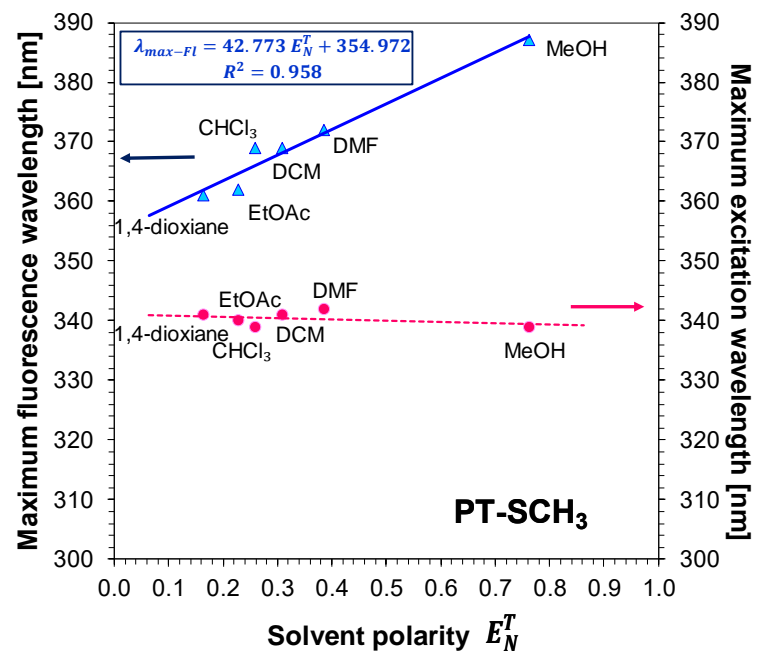

(a)

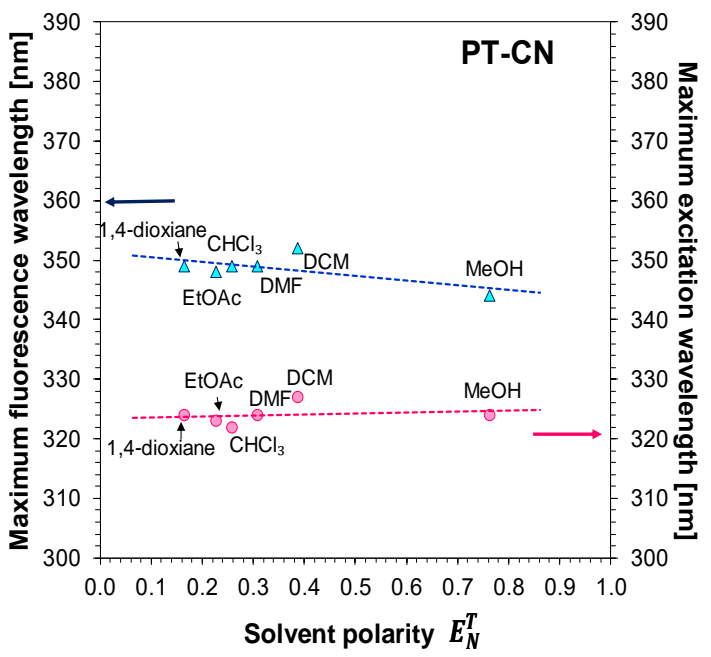

(b)

Figure 6. Dependence of the location of the maximum intensity of the emission and excitation spectra for (a) 2,6-bis(4-methylsulphanylphenyl)pyridine (PT-SCH 3$)$ and (b) 2,6-bis(4-cyanophenyl)pyridine (PT-CN) on the polarity of the solvents (scale $E_{N}^{T}$ ).

The polarization of the pyridine derivatives with electron-donor groups is higher than that of the derivatives with electron-withdrawing substituents. This phenomenon causes the ICT transition energy to be lower (the higher the polarization of the molecule, the lower the energy of the electronic transition). Besides, the change in the dipole moment of the molecule during the excitation can be significant, which in turn causes a reduction in the energy of the excited state (solvent relaxation) and thus a smaller energy of the radial return of the molecule to the ground state.

Consequently, the polarization of the molecule with two electron-donor groups at the ends and an electron-acceptor group in the centre is more significant than when the molecule is equipped with a bare phenyl ring-hence, the observed effects appear.

\subsection{Monitoring of Free-Radical Photopolymerization Using 2,6-Diphenylpyridine Derivatives}

Subsequently, studies on the applicability of 2,6-diphenylpyridine derivatives as molecular fluorescent probes for monitoring the free-radical photopolymerization of acrylate monomers (TMPTA) using Fluorescence Probe Technology were carried out [52,53]. During the photopolymerization process, polarity changed and viscosity dramatically increased because the liquid monomer transforms into a solid polymer and, as mentioned above, polarity generally decreases. Therefore, fluorescent molecular 
sensors should respond to a change in viscosity and/or polarity by changing the characteristics of the fluorescence spectra.

The free-radical photopolymerization process was carried out in UV-LED irradiation with a maximum emission of $320 \mathrm{~nm}$. Generally, the bathochromic or hypsochromic shifts of emission spectra from fluorescent probes depend on the nature and character of the probe, as observed during the free-radical photopolymerization process [44]. The following figure, Figure 7, indicates the monitoring of the changes of the fluorescence spectra of selected 2,6-bis-phenylpyridine compounds ( $\mathrm{PT}-\mathrm{SCH}_{3}$ and PT-CN) during the free-radical photopolymerization of TMPTA monomers under irradiation of $320 \mathrm{~nm}$. Information on other potential sensors can be found in the Supplementary Materials (Figures S32-S38). During the photopolymerization process, a decrease in fluorescence intensity was generally observed for these probes. A slight shift of emission spectra $\left(\Delta \lambda_{\max }=5 \mathrm{~nm}\right)$, however, was obtained for 2,6-bis(4-methylsulphanylphenyl)pyridine $\left(\mathrm{PT}^{-} \mathrm{SCH}_{3}\right)$ (Figure 7a).

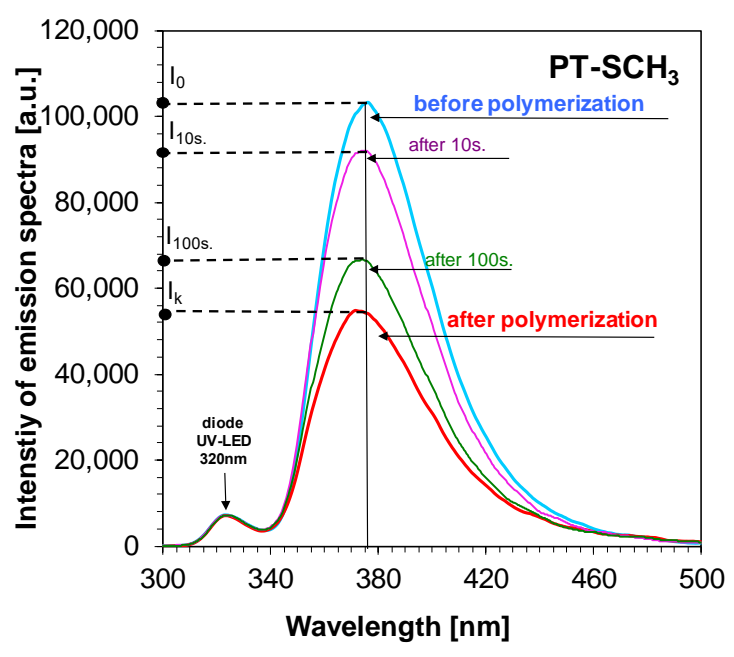

(a)

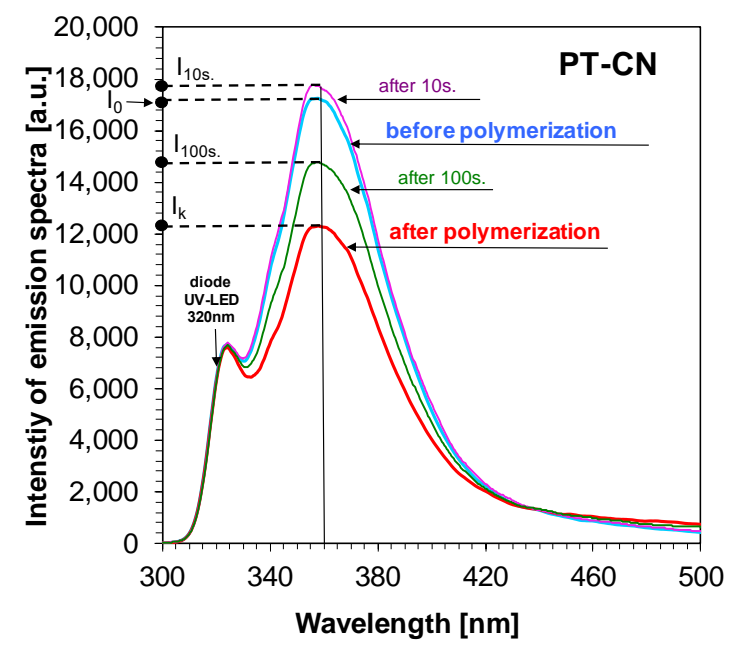

(b)

Figure 7. Changes of fluorescence spectra during free-radical photopolymerization of the TMPTA monomer under irradiation of $320 \mathrm{~nm}$ : (a) 2,6-bis(4-methylsulphanylphenyl)pyridine $\left(\mathrm{PT}_{-} \mathrm{SCH}_{3}\right)$; (b) 2,6-bis(4-cyanophenyl)pyridine (PT-CN).

In consequence, the fluorescence intensity ratio $(\mathrm{R})$ was applied as an indicator of polymerization progress. R was defined as the ratio of fluorescence intensity at a shorter wavelength $\left(\lambda_{1}\right)$ to the intensity at a longer wavelength $\left(\lambda_{2}\right)$, both located on the opposite sides of the fluorescence spectrum maximum. The monitoring wavelengths were determined individually for each probe from the probe fluorescence spectrum taken before monomer polymerization. Thus, the defined $\mathrm{R}$ values started from 1 and increased when the fluorescence spectrum shifted to shorter wavelengths or stayed constant when the spectrum did not shift. Figure 8a shows the effect of the measured free radical photopolymerization in real time, using the fluorescence intensity ratio $(\mathrm{R})$ as progress indicator. It can be clearly seen that, depending on the type of substituents on the 2,6-diphenylpyridine moiety, the compounds either shifted or not shifted their fluorescence spectrum before and after photopolymerization, which is reflected in the ratio span between the uncured and cured states of the composition (Figure 8a). From among the probes studied, the sensor $\mathrm{PT}-\mathrm{SCH}_{3}$ can be used to monitor the kinetics of the free-radical photopolymerization process using the increase of the ratio $(\mathrm{R})$ with the progress of monomer polymerization. For the rest of the pyridine derivatives, this was impossible because the emission spectra of these compounds did not change position during the polymerization (Figure 8 and Table 4). 


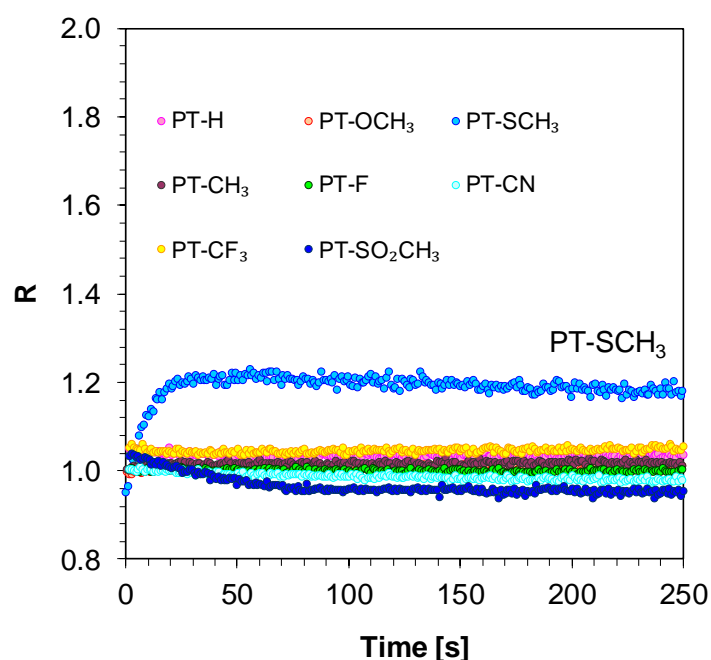

(a)

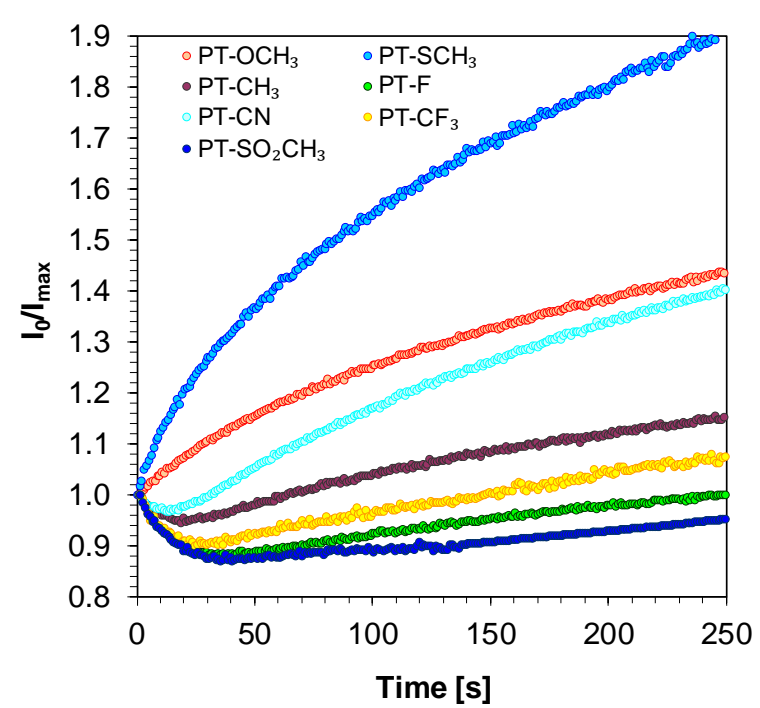

(b)

Figure 8. Monitoring the free-radical photopolymerization of the TMPTA monomer under $320 \mathrm{~nm}$ by FPT, using the 2,6-bis(4-methylsulphonylphenyl)pyridine as fluorescent sensor and (a) the R parameter and (b) the $\mathrm{I}_{0} / \mathrm{I}_{\max }$ parameter.

Table 4. Spectroscopic data of 2,6-diphenylpyridine derivatives during the free-radical photopolymerization process.

\begin{tabular}{|c|c|c|c|c|c|c|c|}
\hline Sensor & $\begin{array}{c}\lambda_{\text {max-BEFORE }} \\
{[\mathrm{nm}]}\end{array}$ & $\begin{array}{c}\text { Intensity } \\
@ \lambda_{\text {max-BEFORE }} \\
\text { [a.u.] }\end{array}$ & $\begin{array}{c}\lambda_{\text {max-AFTER POL }} \\
{[\mathrm{nm}]}\end{array}$ & $\begin{array}{l}\text { Intensity } \\
@ \lambda_{\text {max-AFTER }} \\
\text { [a.u.] }\end{array}$ & $\begin{array}{c}\left|\Delta \mathrm{I}_{\text {max }}\right| \\
{[\text { a.u.] }}\end{array}$ & $\begin{array}{c}\Delta \mathbf{I}_{\max } \\
{[\%]}\end{array}$ & $\begin{array}{c}\Delta \lambda_{\max } \\
{[\mathrm{nm}]}\end{array}$ \\
\hline \multicolumn{8}{|c|}{ Free-radical photopolymerization process of TMPTA under $320 \mathrm{~nm}$} \\
\hline PT-H & 348 & 4710 & 348 & 6072 & 1362 & 29 & 0 \\
\hline $\mathrm{PT}^{-O C H} \mathrm{OCH}_{3}$ & 366 & 43,331 & 366 & 30,018 & 13,312 & 31 & 0 \\
\hline $\mathrm{PT}_{-} \mathrm{SCH}_{3}$ & 376 & 103,347 & 372 & 54,747 & 48,600 & 47 & 5 \\
\hline $\mathrm{PT}-\mathrm{CH}_{3}$ & 356 & 21,093 & 356 & 18,294 & 2799 & 13 & 0 \\
\hline PT-F & 352 & 9366 & 352 & 9394 & 27 & 0 & 0 \\
\hline PT-CN & 358 & 17,255 & 358 & 12,291 & 4964 & 29 & 0 \\
\hline $\mathrm{PT}-\mathrm{CF}_{3}$ & 340 & 4026 & 340 & 3769 & 257 & 6 & 0 \\
\hline PT-SO ${ }_{2} \mathrm{CH}_{3}$ & 364 & 5191 & 364 & 5779 & 588 & 11 & 0 \\
\hline
\end{tabular}

$\Delta \mathrm{I}_{\max }$-changes in fluorescence intensity expressed as a percentage in relation to the initial value before polymerization; $\left|\Delta \mathrm{I}_{\max }\right|$-difference in fluorescence intensity before and after the photopolymerization process; $\Delta \lambda_{\max }$ - position of the maximum fluorescence before and after the photopolymerization process.

Therefore, in the case of other 2,6-diphenylpyridine derivatives, the normalised intensity $\left(\mathrm{I}_{0} / \mathrm{I}_{\max }\right)$ parameter can be applicable to the curing processes under stationary measurement conditions. Figure $8 \mathrm{~b}$ shows the kinetic profiles of the photopolymerization process, obtained using normalised fluorescence intensity $\left(\mathrm{I}_{0} / \mathrm{I}_{\max }\right)$ as the polymerization progress indicator. All derivatives except one, 2,6-diphenylpyridine (PT-H), exhibit a large enough change in the parameter $\mathrm{I}_{0} / \mathrm{I}_{\max }$ during monomer polymerization to be applied as fluorescent sensors for monitoring free-radical photopolymerization.

In conclusion, based on these experiments, it was shown that the changes in emission spectra for $\mathrm{PT}_{-} \mathrm{SCH}_{3}$ are caused by changes in the polarity and viscosity of the surrounding environment. Conversely, for the rest of the 2,6-diphenylpyridine derivatives, changes in emission spectra are dictated only by changes in viscosity, as shown for the example of the PT-CN derivative in the spectroscopic experiment with solvents with different polarity. Therefore, the effect of substituents on the sensitivity of the 2,6-diphenylpyridine derivatives as sensors during free-radical photopolymerization is significant. Nevertheless, depending on the type of substituents, either the fluorescence intensity 
ratio $(\mathrm{R})$ or the normalised intensity $\left(\mathrm{I}_{0} / \mathrm{I}_{\max }\right)$ can be used as quantitative indicators of the free-radical polymerization progress.

\subsection{Monitoring of Cationic Photopolymerization Using 2,6-Diphenylpyridine Derivatives-Is It Possible?}

Similar measurements of the applicability of 2,6-diphenylpyridine derivatives as potential fluorescent molecular sensors for monitoring the kinetics of the cationic photopolymerization processes of vinyl monomer (TEGDVE) were carried out. As with free-radical photopolymerization, the compositions were irradiated with UV-LED with a maximum emission of $320 \mathrm{~nm}$. Theoretically, every process that causes a change in the system's polarity or micro-viscosity should be able to be monitored by fluorescent sensors. Depending on the type of process and monitoring parameters, however, the relevant structure and characteristics of the sensors are required. This is exactly what happened during the monitoring of cationic photopolymerization with 2,6-diphenylpyridine derivatives. The behaviours of 2,6-diphenylpyridine derivatives during the cationic photopolymerization of the TEGDVE monomer turned out to be different from the behaviour of the same compounds during the free-radical photopolymerization of the acrylate monomer TMPTA studied previously. Upon comparison of the fluorescence spectra of the 2,6-diphenylpyridine derivatives at different irradiation times, it was noted that the fluorescence intensity of all investigated compounds decreased significantly during cationic photopolymerization. For compounds 2,6-bis(4-methoxyphenyl)pyridine (PT-OCH ${ }_{3}$ ), 2,6-bis(4-methylsulphanylphenyl)pyridine (PT-SCH 3 ), 2,6-bis(p-tolyl)pyridine $\left(\mathrm{PT}^{-} \mathrm{CH}_{3}\right)$ and 2,6-bis(4-fluorophenyl)pyridine (PT-F), the following was observed: a dramatic decrease in fluorescence intensity at maximum emission fluorescence located at shorter wavelengths $\left(\lambda_{\text {max-short }}\right)$ below $400 \mathrm{~nm}$, and simultaneous appearance and increase of fluorescent intensity of a completely new fluorescence band at longer wavelengths $\left(\lambda_{\max -l o n g}\right)$ (Figure 9a,d,g,j). Moreover, during the cationic photopolymerization process for the 2,6-diphenylpyridine (PT-H) and for compounds with electron-withdrawing substituents, i.e., $\mathrm{PT}-\mathrm{CF}_{3}$ and $\mathrm{PT}_{-} \mathrm{SO}_{2} \mathrm{CH}_{3}$, an increase of the fluorescence intensity at longer wavelengths was observed. As these compounds exhibit very weak fluorescence prior to the cationic photopolymerization of vinyl monomers, the fluorescent spectrum in shorter wavelengths was not studied. Only when the photocurable samples were exposed under UV light was there a significant increase in fluorescence intensity (Figure 10) observed. This clearly indicates that substitution in the phenyl rings at the para-position of the 2,6-diphenylpyridine moiety plays an important role in the generation of a push-pull effect in the excited states of the compounds. The highest sensitivity was achieved in the case of $\mathrm{PT}-\mathrm{OCH}_{3}$ containing an electron-donating methoxy group in the para-position of the phenyl rings. This is well illustrated in Table 5, showing the effect of Hammett substituent constants $\left(\sigma_{\mathrm{p}}\right)$ on the speed of the decrease of fluorescent intensity localised at shorter maximum emissions of the 2,6-diphenylpyridine derivatives.

At this stage of the research, the question arose: is it possible to monitor the kinetics of the cationic photopolymerization process using the FPT method with pyridine derivatives? From a practical point of view, the compound used as a fluorescent sensor to track changes in polymerization kinetics should only be sensitive to changes associated with this process. Thus, for example, it should be sensitive to changes in polarity and/or viscosity in the entire monomer conversion range. Based on the recorded data, however, it can be seen that when the light is switched on to initiate the photopolymerization process, the fluorescence spectrum localised at the UV-A region of the sensors $\left(\mathrm{PT}^{-\mathrm{OCH}_{3}}\right),\left(\mathrm{PT}^{-\mathrm{SCH}_{3}}\right)$, $\left(\mathrm{PT}-\mathrm{CH}_{3}\right)$ and $(\mathrm{PT}-\mathrm{F})$ decreases dramatically. Moreover, for these compounds, the simultaneous appearance of a completely new fluorescence band located in a more extended wavelength range is observed (Figure 9b,c,e,f,h,i,k,l). 


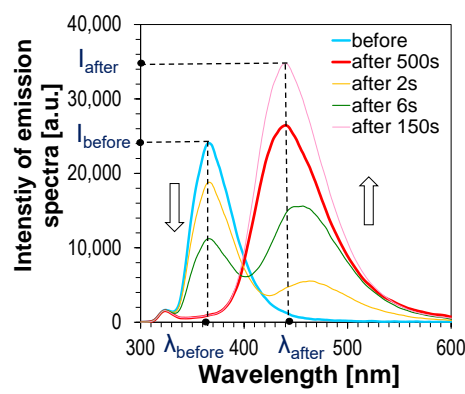

(a)

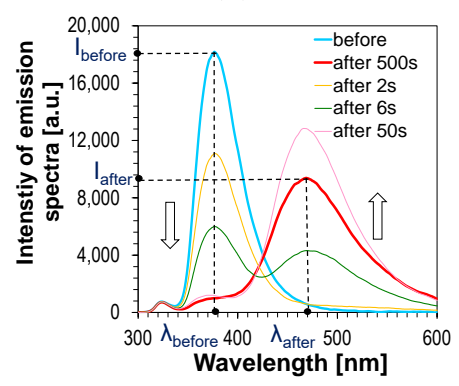

(d)

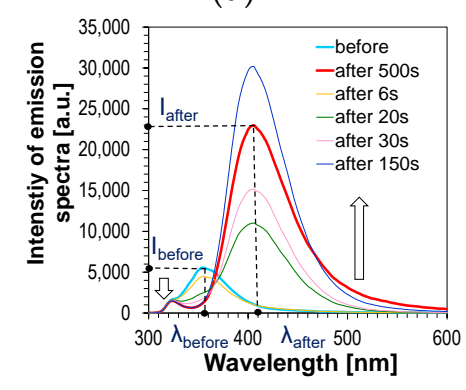

(g)

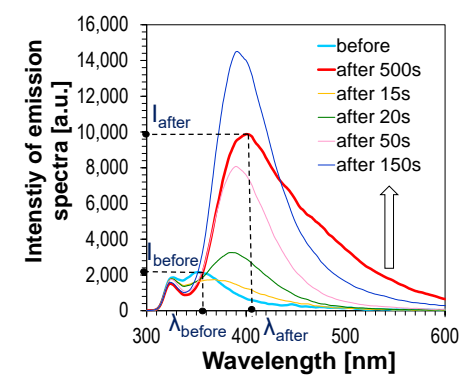

(j)

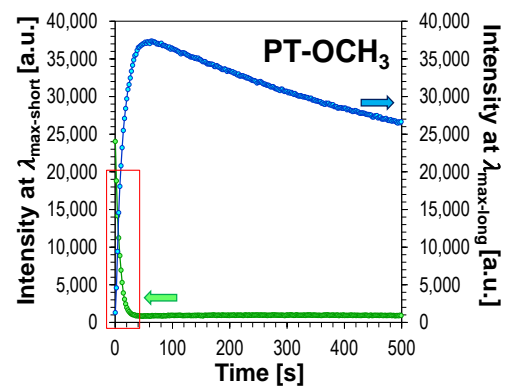

(b)

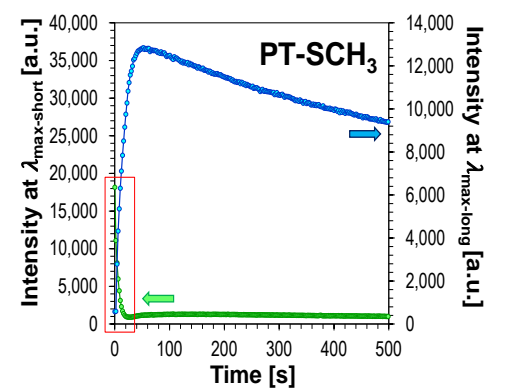

(e)

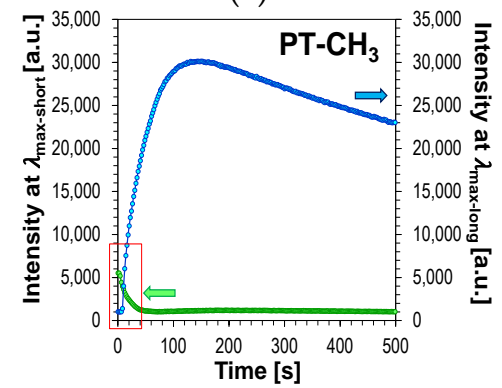

(h)

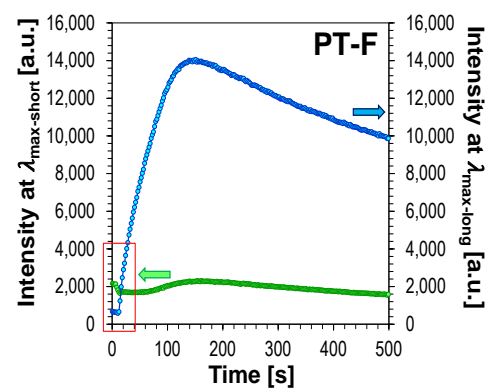

(k)

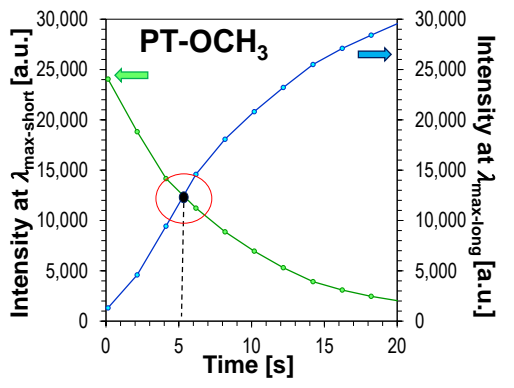

(c)

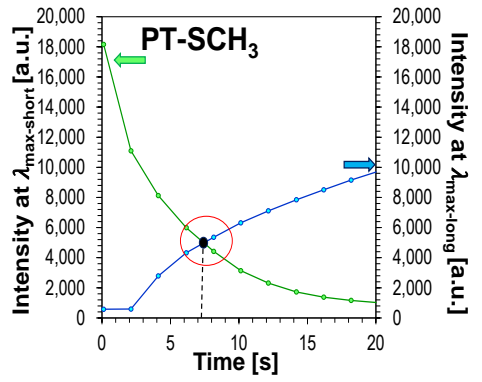

(f)

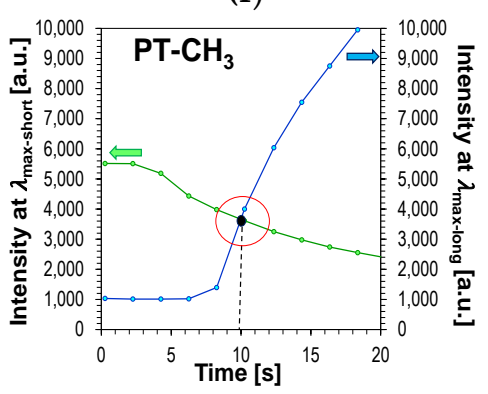

(i)

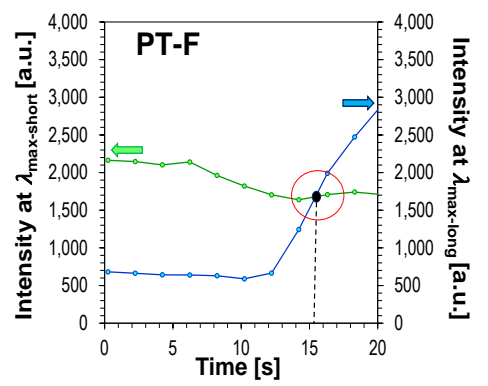

(1)

Figure 9. $(\mathbf{a}, \mathbf{d}, \mathbf{g}, \mathbf{j})$ Changes of fluorescence spectra of the 2,6-diphenylpyridine derivatives during cationic photopolymerization of TEGDVE monomer under irradiation at $320 \mathrm{~nm} ;(\mathbf{b}, \mathbf{c}, \mathbf{e}, \mathbf{f}, \mathbf{h}, \mathbf{i}, \mathbf{k}, \mathbf{l})$ monitoring cationic photopolymerization of TEGDVE monomer under $320 \mathrm{~nm}$ by FPT, using the 2,6-diphenylpyridine derivatives as the fluorescent sensors. 


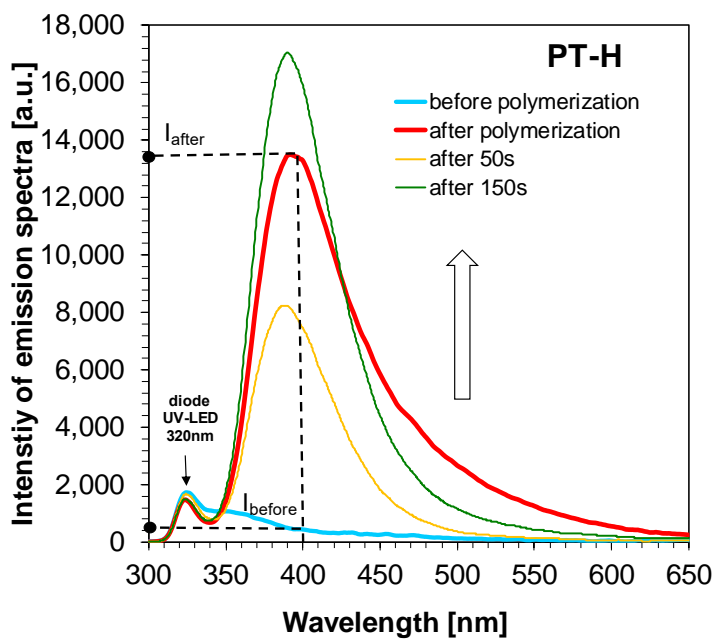

(a)

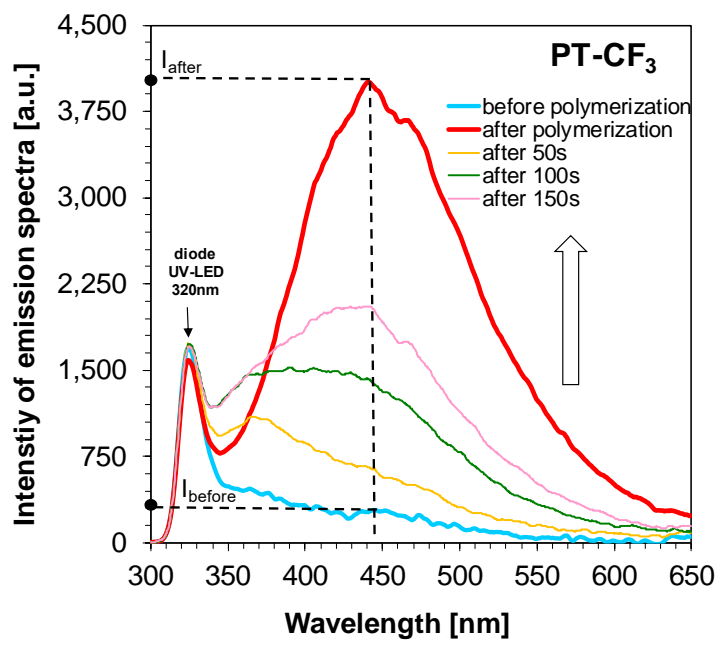

(c)

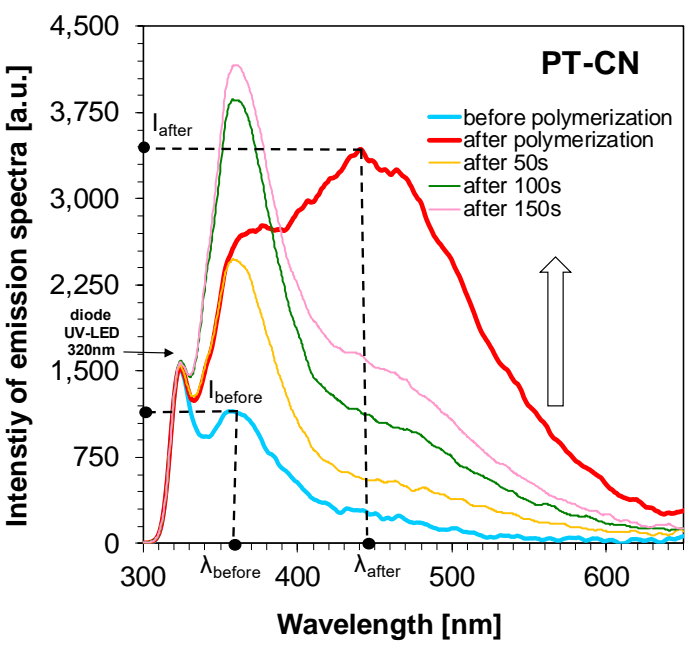

(b)

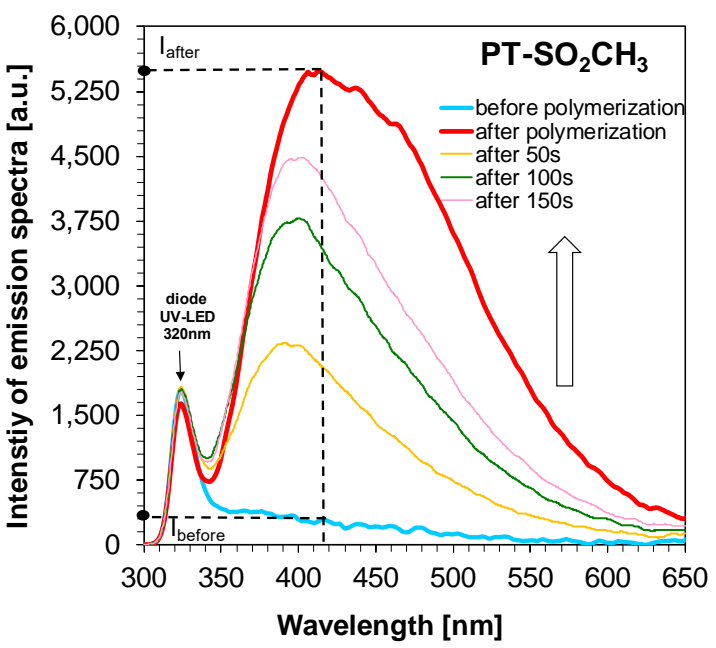

(d)

Figure 10. Changes of fluorescence spectra during cationic photopolymerization of TEGDVE monomer under irradiation $320 \mathrm{~nm}$ for (a) PT-H sensor; (b) PT-CN sensor; (c) $\mathrm{PT}_{-} \mathrm{CF}_{3}$ sensor; (c) $\mathrm{PT}-\mathrm{SO}_{2} \mathrm{CH}_{3}$ sensor.

Table 5. Spectroscopic data of the 2,6-diphenylpyridine derivatives during the cationic photopolymerization processes.

\begin{tabular}{|c|c|c|c|c|c|c|c|c|c|}
\hline Sensor & $\begin{array}{l}\lambda_{\text {max-short-BEFORE }} \\
{[\mathrm{nm}]}\end{array}$ & $\underset{\substack{\text { I } \\
\lambda_{\text {max-short-BEFORE }} \\
\text { [a.u.] }}}{\text { I }}$ & $\begin{array}{c}\text { I } \\
\substack{\text { max-short-AFTER } \\
\text { [a.u.] }}\end{array}$ & $\begin{array}{c}\lambda_{\text {max-long }} \\
{[\mathrm{nm}]}\end{array}$ & $\underset{\substack{\text { @ax-long-BEFORE } \\
\text { [a.u.] }}}{\text { I }}$ & $\begin{array}{c}\text { I } \\
\substack{\text { max-long-AFTER } \\
\text { [a.u.] }}\end{array}$ & $\begin{array}{c}\Delta \lambda_{\max } \\
{[\mathrm{nm}]}\end{array}$ & $\mathrm{d} \mathrm{I} / \mathrm{dt}$ & $\sigma_{\mathrm{p}}$ \\
\hline PT-H & \multicolumn{3}{|c|}{ no absorption at $\lambda_{\text {max-short }}$} & 392 & 550 & 13,490 & 0 & 179 & 0.000 \\
\hline $\mathrm{PT}-\mathrm{OCH}_{3}$ & 366 & 24,070 & 960 & 440 & 1330 & 26,460 & 74 & 2034 & -0.268 \\
\hline PT-SCH ${ }_{3}$ & 377 & 18,180 & 990 & 469 & 590 & 9380 & 92 & 457 & 0.000 \\
\hline PT-CH 3 & 353 & 2570 & 1060 & 406 & 1080 & 22,980 & 53 & 614 & -0.170 \\
\hline PT-F & 352 & 2160 & 1610 & 400 & 670 & 9880 & 48 & 216 & 0.062 \\
\hline PT-CN & 356 & 1150 & 2490 & 441 & 290 & 3430 & 85 & 12 & 0.660 \\
\hline $\mathrm{PT}-\mathrm{CF}_{3}$ & \multirow{2}{*}{\multicolumn{3}{|c|}{$\begin{array}{l}\text { no absorption at } \lambda_{\text {max-short }} \\
\text { no absorption at } \lambda_{\text {max-short }}\end{array}$}} & 441 & 270 & 4000 & 0 & 16 & 0.540 \\
\hline PT-SO ${ }_{2} \mathrm{CH}_{3}$ & & & & 412 & 260 & 5490 & 0 & 50 & 0.720 \\
\hline
\end{tabular}

$\Delta \lambda_{\max }=\lambda_{\text {max-long-BEFORE }}-\lambda_{\max -\text { short-AFTER; }}\left(\mathrm{dIntensity}\left(@ \lambda_{\max }\right) / \mathrm{dt}\right)_{\max }=\mathrm{dI} / \mathrm{dt} ; \sigma_{\mathrm{p}}-$ Hammett substituent constants [54].

Therefore, it is crucial to answer the question of what it is we are monitoring using this group of compounds during the cationic polymerization process. Based on earlier research, it is known that the developed derivatives exhibit photostability when exposed to both $320 \mathrm{~nm}$ light and UV-C light of $300 \mathrm{~nm}$. Therefore, the likelihood of photobleaching has been excluded. During the photocleavage process of iodonium salt, at the stage of initiation of cationic polymerization, strong protic acids are 
generated. It was likely that the monitored response of the analysed sensors relates to the online monitoring of the strong acid generation rate at the initiation stage. Consequently, the responses of the sensors do not track the consumption of monomers or do not monitor increase the degree of conversion and progress of polymerization. In order to carry out more extensive research on the effects of the environment on the spectroscopic response of 2,6-diphenylpyridine derivatives, the effect of $\mathrm{pH}$ on the fluorescence characteristics of the developed derivatives was investigated.

\subsection{Applicability of 2,6-Diphenylpyridine Derivatives as Fluorescent $p H$ Sensors}

The next step was to test the applicability of the new 2,6-diphenylpyridine derivatives for monitoring $\mathrm{pH}$ changes. To this end, 2,6-bis-(4-methoxyphenyl)pyridine $\left(\mathrm{PT}^{-} \mathrm{OCH}_{3}\right)$, which has an electron-donating substituent located in the phenyl rings, was selected. As shown in Figure 11, the maximum emission wavelength of 2,6-bis-(4-methoxyphenyl)pyridine $\left(\mathrm{PT}^{-} \mathrm{OCH}_{3}\right)$ is located at $354 \mathrm{~nm}$ for $\mathrm{pH} 7.0$, with an intensity of $3.23 \times 10^{5}$ [a.u.]. Upon decreasing the $\mathrm{pH}$ from 7.0 to 1.0 , however, the emission spectrum of 2,6-bis-(4-methoxyphenyl)pyridine, which is $104 \mathrm{~nm}$, bathochromically shifted to $458 \mathrm{~nm}$, which is a sixfold increase of the intensity of fluorescence, accompanied by the gradual disappearance of the peak of the emission located at $354 \mathrm{~nm}$ (Figure 11 and Table 6). The large bathochromic shift of the maximum of the fluorescence spectrum was attributed to the enhanced ICT effect because of the $\mathrm{H}^{+}$-binding-induced enhancement of the electron-withdrawing ability of pyridine. The obtained red shift of the spectrum of PT- $\mathrm{OCH}_{3}$ provided a good opportunity to achieve ratiometric detection in the acidic region. The large shift in the fluorescence emission peak caused a variation in emission colour. With decreasing $\mathrm{pH}$, the colour of the $\mathrm{PT}-\mathrm{OCH}_{3}$ sensor in the solution changed from UV to blue (Figure 12). Therefore, the 2,6-bis-(4-methoxyphenyl)pyridine ( $\mathrm{PT}^{\left.-\mathrm{OCH}_{3}\right)}$ can act as a "naked-eye" fluorescence sensor for acidic $\mathrm{pH}$ environments.

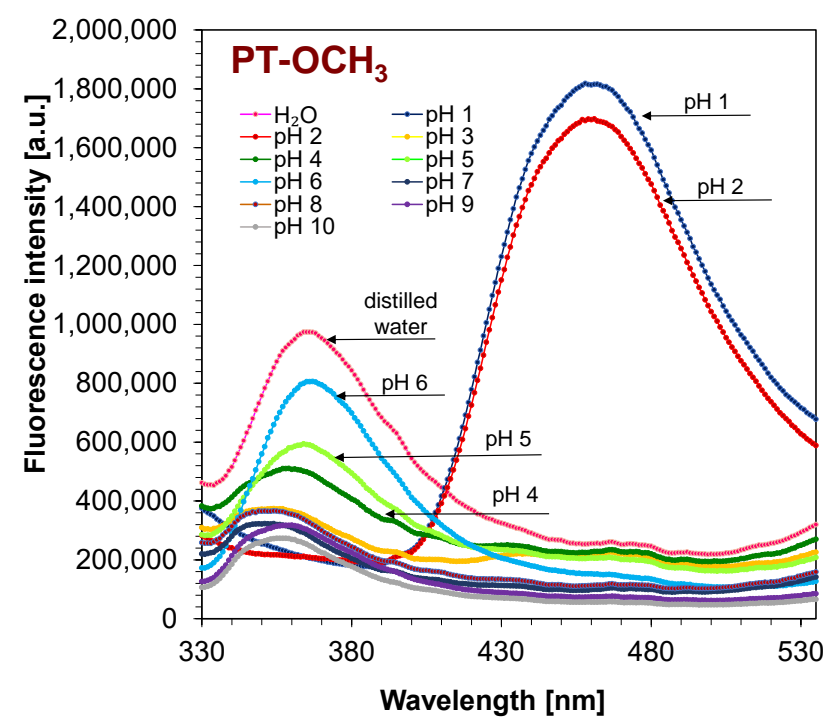

Figure 11. Comparison of fluorescence spectrum maximum location for compound $\mathrm{PT}-\mathrm{OCH}_{3}$ in acetonitrile and $\mathrm{pH}$ in a range of $1-10$. 
Table 6. Comparison of the maximum intensity and its location for the $\mathrm{PT}-\mathrm{OCH}_{3}$ compound at different $\mathrm{pHs}$.

\begin{tabular}{ccccc}
\hline & \multicolumn{4}{c}{ PT-OCH } \\
\cline { 2 - 5 } $\mathbf{p H}$ & $\begin{array}{c}\lambda_{\max } \\
{[\mathbf{n m}]}\end{array}$ & $\begin{array}{c}\mathbf{I}_{\max } \\
\text { [a.u.] }\end{array}$ & $\begin{array}{c}\Delta \boldsymbol{\lambda}_{\max } \\
{[\mathbf{n m}]}\end{array}$ & $\begin{array}{c}\Delta \mathbf{I}_{\max } \\
\text { [a.u.] }\end{array}$ \\
\hline $\mathrm{H}_{2} \mathrm{O}$ (distilled water) - reference & 364 & $9.74 \times 10^{5}$ & 0 & 0 \\
1 & 458 & $1.82 \times 10^{6}$ & 94 & $8.44 \times 10^{5}$ \\
2 & 461 & $1.70 \times 10^{6}$ & 97 & $7.24 \times 10^{5}$ \\
3 & 354 & $3.74 \times 10^{5}$ & 10 & $1.68 \times 10^{5}$ \\
4 & 359 & $5.11 \times 10^{5}$ & 5 & $4.63 \times 10^{5}$ \\
5 & 365 & $5.94 \times 10^{5}$ & 1 & $3.80 \times 10^{5}$ \\
6 & 367 & $1.68 \times 10^{5}$ & 3 & $8.06 \times 10^{5}$ \\
7 & 354 & $3.23 \times 10^{5}$ & 10 & $6.51 \times 10^{5}$ \\
8 & 354 & $3.67 \times 10^{5}$ & 10 & $6.07 \times 10^{5}$ \\
9 & 360 & $3.18 \times 10^{5}$ & 4 & $6.56 \times 10^{5}$ \\
10 & 358 & $2.73 \times 10^{5}$ & 6 & $7.00 \times 10^{5}$ \\
\hline
\end{tabular}

$\lambda_{\max -\mathrm{Fl}}$ - position of maximum fluorescence intensity; $\mathrm{I}_{\max }$-intensity of the fluorescence at $\lambda_{\max -\mathrm{Fl}} ; \Delta \lambda_{\max }$ - difference between the position of the maximum fluorescence of the PT- $-\mathrm{OCH}_{3}$ compound in the reference sample (in distilled water) and the maximum of fluorescence in buffers at different $\mathrm{pHs}[\mathrm{nm}] ; \Delta \mathrm{I}_{\max }$ - difference between the maximum fluorescence intensity of the $\mathrm{PT}-\mathrm{OCH}_{3}$ compound in a reference sample (in distilled water) and the maximum intensity of the $\mathrm{PT}-\mathrm{OCH}_{3}$ compound in buffers at different $\mathrm{pHs}$.

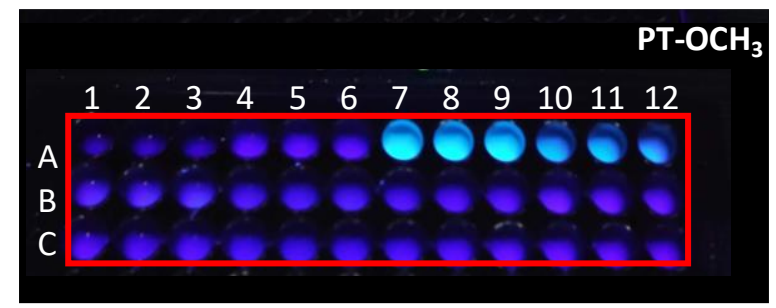

Figure 12. Dependence of the emission spectra of the $\mathrm{PT}-\mathrm{OCH}_{3}$ on different $\mathrm{pH}$ environments. Photograph illustrates the fluorescence intensity of the $\mathrm{PT}-\mathrm{OCH}_{3} \mathrm{Compound}$ in acetonitrile under a UV-LED lamp with a maximum emission of $365 \mathrm{~nm}$ in an environment of various $\mathrm{pH}$ values: A1-A3 acetonitrile; A4-A6 $\mathrm{H}_{2} \mathrm{O}$; $\mathrm{A} 7-\mathrm{A} 9 \mathrm{pH}$ 1; $\mathrm{A} 10-\mathrm{A} 12$ pH 2; B1-B3 pH 3; B4-B6 pH 4; B7-B9 pH 5; B10-B12 pH 6; C1-C3 pH 7; C4-C6 pH 8; C7-C9 pH 9; C10-C12 pH 10.

The above results allowed us to propose a mechanism of interactions between the sensor and the acidic environment properties. We postulate that, under acidic conditions, the pyridine $\mathrm{N}$ atom is protonated in the form of $\mathrm{NH}^{+}$. Protonated pyridine acts as an electron acceptor and the phenyl rings with electron-donating substituents act as electron donors. This mechanism can be responsible for the sensors' capacity for real-time $\mathrm{pH}$ monitoring in a strong acidic region. In order to examine whether these $\mathrm{pH}$-dependent emission ratio changes of the 2,6-bis-(4-methoxyphenyl)pyridine $\left(\mathrm{PT}-\mathrm{OCH}_{3}\right)$ and 2,6-bis(4-methylsulphanylphenyl)pyridine $\left(\mathrm{PT}-\mathrm{SCH}_{3}\right)$ are useful for monitoring cationic photopolymerization, and especially the process of decomposition of iodonium salt with the generation of a strong protic acid, the relevant experiments were carried out.

Most fluorescence $\mathrm{pH}$ probes are practical in a near-neutral $\mathrm{pH}$ region, and probes for detecting the $\mathrm{pH}$ changes in the acidic range are limited [55]. Moreover, fluorescence $\mathrm{pH}$ sensors are still subject to limitations based on their limited photostability. Thus, developing photostability fluorescent probes possessing large Stokes' shift for monitoring acid $\mathrm{pH}$ is of great importance. The investigated pyridines meet these requirements due to their photostability, the significant bathochromic shift around $90 \mathrm{~nm}$ (Figure 13), and their good solubility in non-polar as well as polar environments. Such properties enable the 2,6-diphenylpiridine derivatives to work as fluorescent acidic $\mathrm{pH}$ sensors in the solution state. 


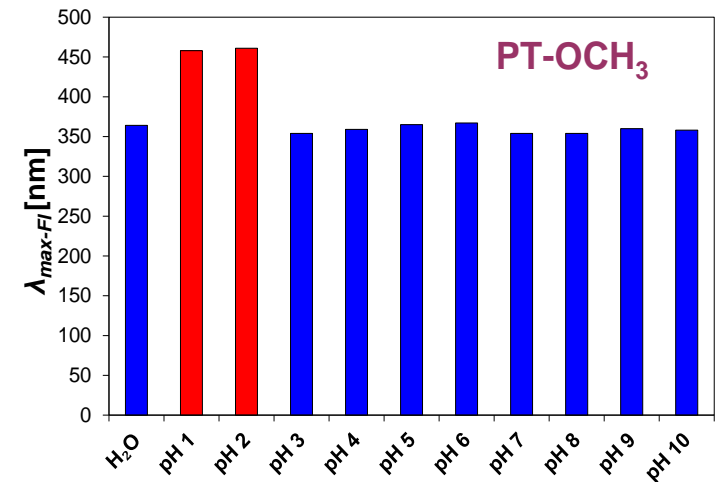

(a)

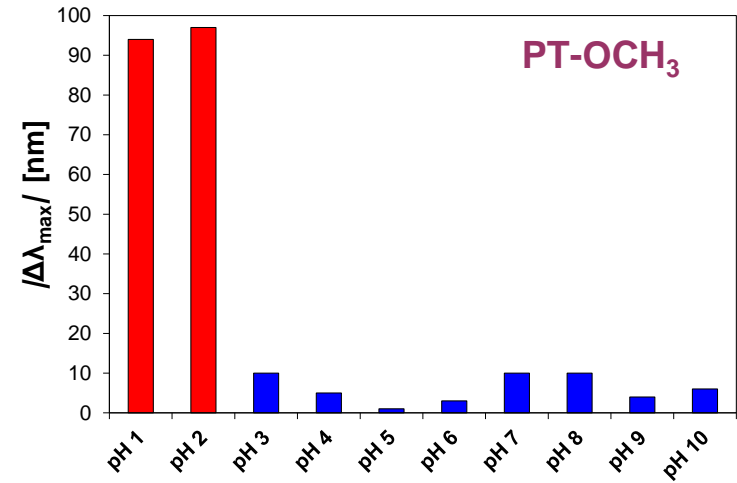

(b)

Figure 13. (a) Position of maximum fluorescence intensity for compound $\mathrm{PT}-\mathrm{OCH}_{3}$ in in distilled water and $\mathrm{pH}$ in a range of 1-10. (b) Difference between the position of the maximum fluorescence of the $\mathrm{PT}-\mathrm{OCH}_{3}$ compound in the reference sample (in distilled water) and the maximum of fluorescence in buffers at different $\mathrm{pH}$.

3.5. 2,6-Diphenylpyridine as Photometric Fluorescent Sensor for the Detection, Determination of Efficiencies and Quantification of Superacid Generation upon Exposure of Iodonium Photoinitiator to Light

Encouraged by these interesting results, a series of experiments were subsequently carried out, which should explain the appearance of a second fluorescence band during the cationic photopolymerization process of the TEGDVE vinyl monomer. For this purpose, three different compositions were prepared and measured by spectroscopic techniques. The first sample was the standard photocurable composition based on fluorescent sensors, a photoinitiator and vinyl monomers (sensor/HIP/TEGDVE); the second sample had sensors dissolved in vinyl monomer (sensor/TEGDVE); and the third sample was based on the investigated sensor with the cationic photoinitiator dissolved in the non-reactive and non-polar solvent (sensor/HIP/toluene). For this purpose, three different compositions were prepared: a standard photocurable composition based on fluorescent sensors, a photoinitiator and vinyl monomer (sensor/HIP/TEGDVE), a probe/photoinitiator (HIP) and another probe/photoinitiator (HIP)/toluene. The first composition probe/HIP/TEGDVE is a standard composition used for monitoring the measurements of the kinetics of the cationic photopolymerization process. The second composition did not contain a photoinitiator, iodonium salt, and thus the composition could not polymerize. The third composition contained the HIP photoinitiator but did not contain a monomer other than a solvent toluene, which, like the TEGDVE monomer, is non-polar. In the final case, the composition cannot be polymerized due to the lack of a monomer. All three types of compositions were irradiated with a UV-LED diode with a maximum emission of $320 \mathrm{~nm}\left(1 \mathrm{~mW} / \mathrm{cm}^{2}\right)$ for 500 seconds. In the case where no HIP photoinitiator was used, no significant changes in emission spectra were observed for the $\mathrm{PT}-\mathrm{OCH}_{3}$ and $\mathrm{PT}-\mathrm{SCH}_{3}$ probes when irradiating the composition with a $320 \mathrm{~nm}$ UV-LED diode (Figure 14,Figure 15,Figure 16). 


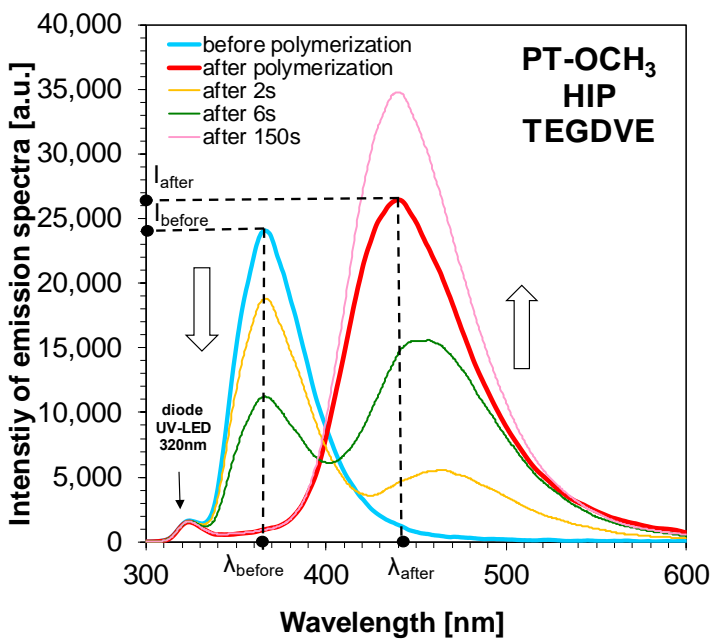

(a)

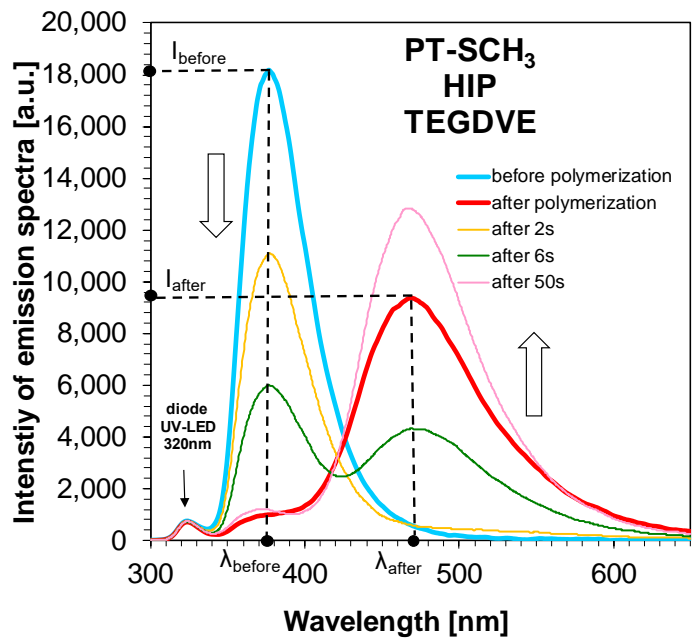

(b)

Figure 14. Changes of fluorescence spectra during cationic photopolymerization of TEGDVE monomer under irradiation at $320 \mathrm{~nm}$ for (a) $\mathrm{PT}-\mathrm{OCH}_{3}$ sensor and (b) $\mathrm{PT}-\mathrm{SCH}_{3}$ sensor.

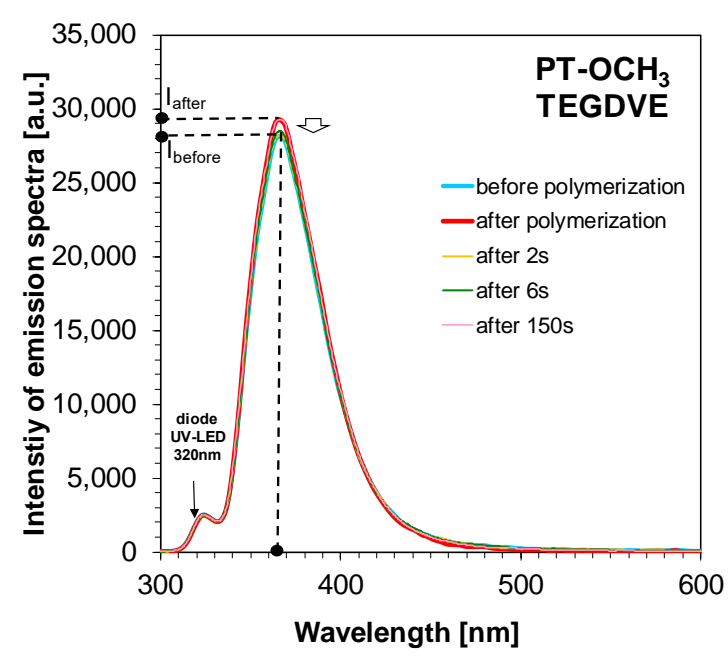

(a)

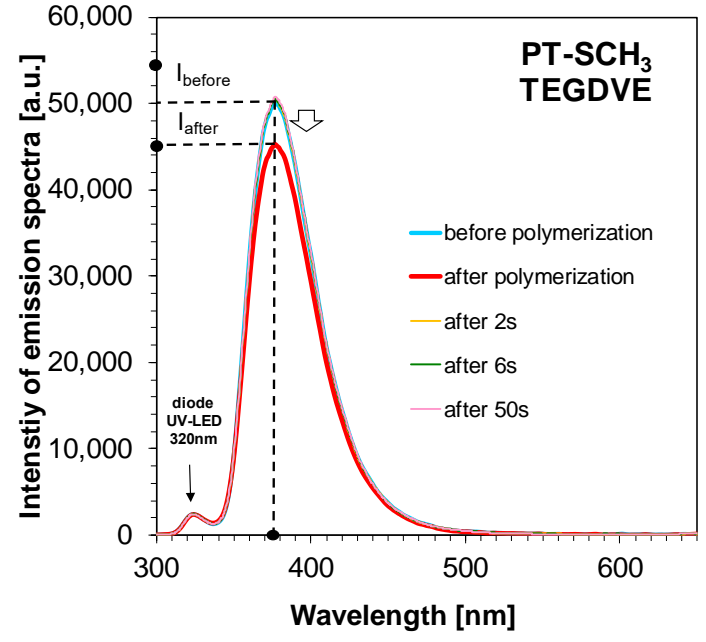

(b)

Figure 15. Changes in emission spectra during irradiation at $320 \mathrm{~nm}$ of the system containing the TEGDVE monomer without the addition of a HIP photoinitiator and (a) the $\mathrm{PT}^{-O C H} \mathrm{H}_{3}$ sensor and (b) the PT- $\mathrm{SCH}_{3}$ sensor. 


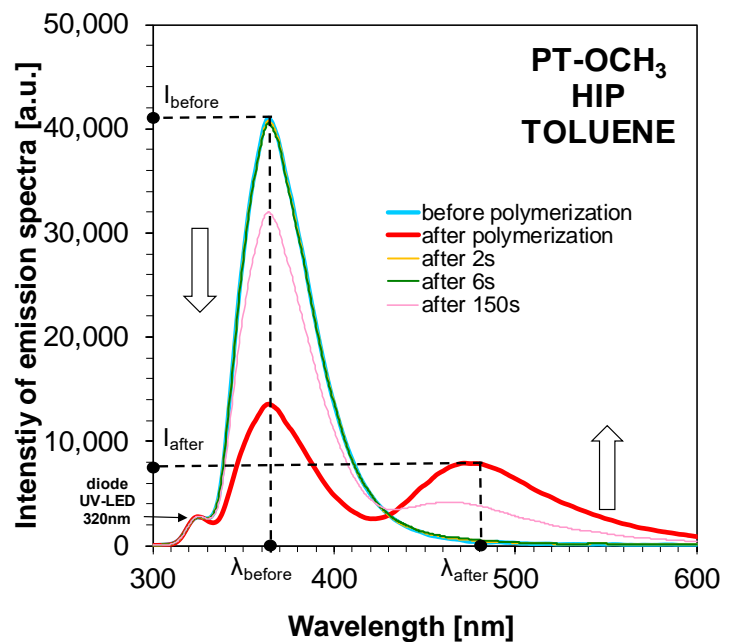

(a)

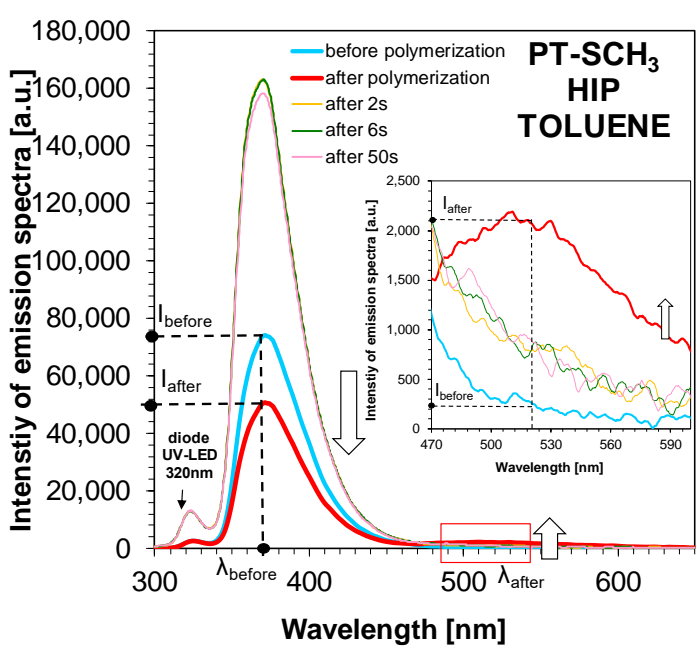

(b)

Figure 16. Changes in emission spectra during irradiation at $320 \mathrm{~nm}$ of the system containing the toluene, HIP photoinitiator and (a) the $\mathrm{PT}-\mathrm{OCH}_{3}$ sensor and (b) the $\mathrm{PT}-\mathrm{SCH}_{3}$ sensor.

When irradiating a composition consisting of $\mathrm{PT}-\mathrm{OCH}_{3} / \mathrm{HIP} /$ toluene and PT-SCH$/ \mathrm{HIP} /$ toluene, a decrease in fluorescence intensity at one wavelength and the appearance of a second fluorescence band at a longer wavelength were observed. During this process, the polarity and viscosity of the system did not change. Therefore, changes in emission spectra had to be caused by the release of a strong protic acid from the diphenyliodonium hexafluorophosphorane (HIP) photoinitiator. During exposure, the photoinitiator photocleaved according to Scheme 3:

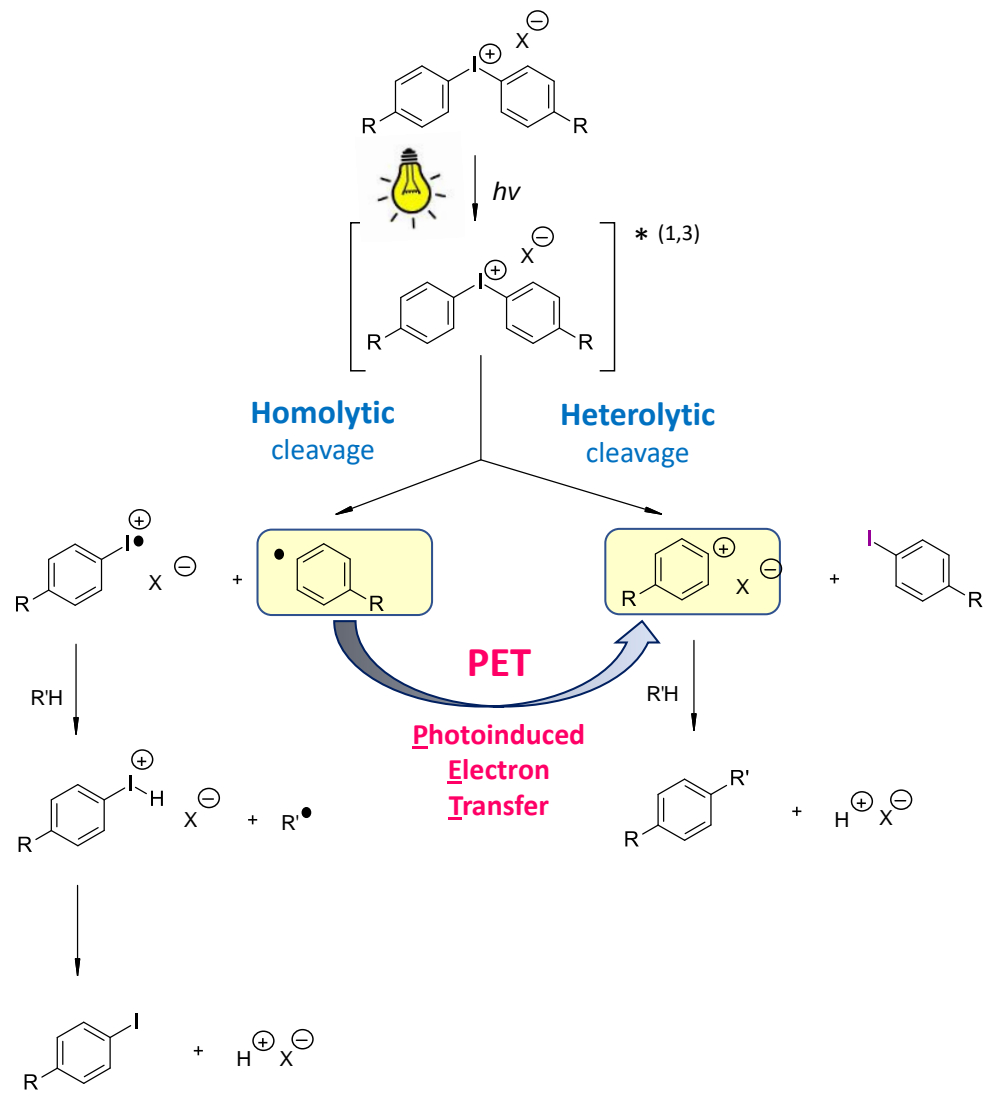

Scheme 3. Photolysis of diphenyliodonium salt as a typical example of onium salt. 
Onium salts are degraded via homolytic or heterolytic cleavage upon light irradiation. During the process of irradiation, a strong protic acid (HX) is generated through the reaction of a proton source (R-H) with the species generated by homolytic (path A) or heterolytic (path B) cleavage. The generated protic acid is responsible for the protonation of the probes $\mathrm{PT}-\mathrm{OCH}_{3}$ and $\mathrm{PT}-\mathrm{SCH}_{3}$.

Moreover, changes in absorbance spectra during photolysis were mainly due to the release of a strong protic acid from the HIP photoinitiator. These studies allow the determination of efficiencies of superacid generation by cationic photoinitiators. Therefore, in order to confirm the sensitivity of new fluorescent probes $\mathrm{PT}-\mathrm{OCH}_{3}$ and $\mathrm{PT}-\mathrm{SCH}_{3}$ on acidic environment properties, photolysis of the $\mathrm{PT}-\mathrm{OCH}_{3}$ compound in acetonitrile with different amounts of cationic photoinitiator was performed. The probe/HIP molar ratios were 0.5:1; 1:1, 2:1, 5:1, 5.4:1, 10:1, 20:1 and 30:1, respectively. The samples were irradiated with a UV-LED diode with a maximum emission of $320 \mathrm{~nm}$, so that the photolysis process was carried out under the same conditions as the cationic photopolymerization process of the TEGDVE monomer. The spectra of the photolysis examples are presented in Figure 17, and the other spectra are presented in the Supplement (Figures S39-S40). During photolysis, in cases where half the amount of photoinitiator was added to the probe solution, no significant changes in absorption spectra were observed (Figure 17a). In the case of the $\mathrm{PT}-\mathrm{OCH}_{3}$ and HIP compositions in a 1:1 molar ratio, it was observed that a band appeared during the photopolysis process at a maximum of about $359 \mathrm{~nm}$. Conversely, at the molar ratio of $\mathrm{HIP} /$ probe 5.4, i.e., as in the measurements of the photopolymerization process of the TEGDVE monomer using Fluorescence Probe Technology, a significant increase in bandwidth at $359 \mathrm{~nm}$ was observed (Figure S40). In turn, the 30-fold excess of the HIP photoinitiator caused an even greater bandwidth increase at $359 \mathrm{~nm}$, which clearly indicates the release of a strong protic acid derived from the HIP photoinitiator (Figure 18).

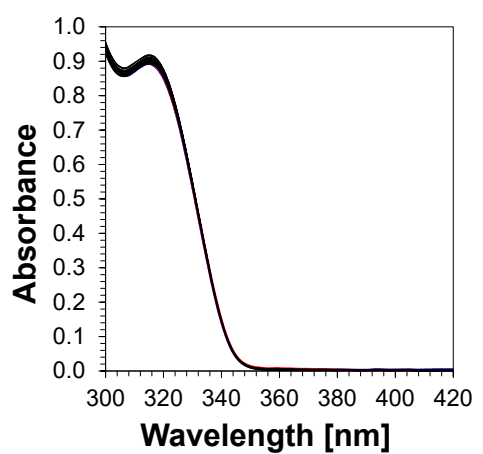

(a)

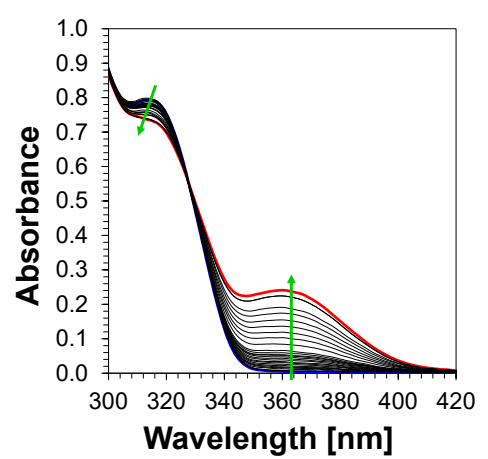

(d)

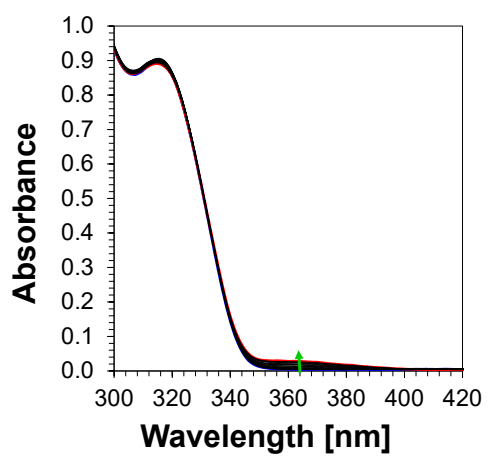

(b)

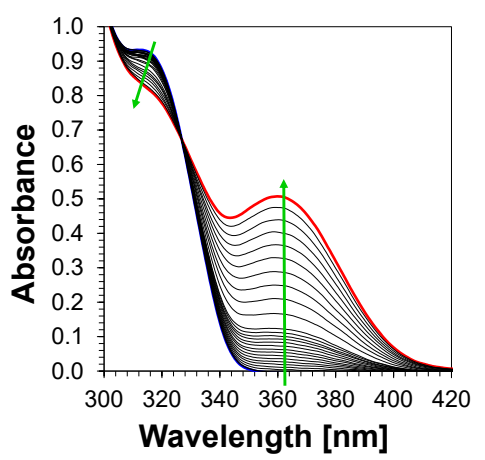

(e)

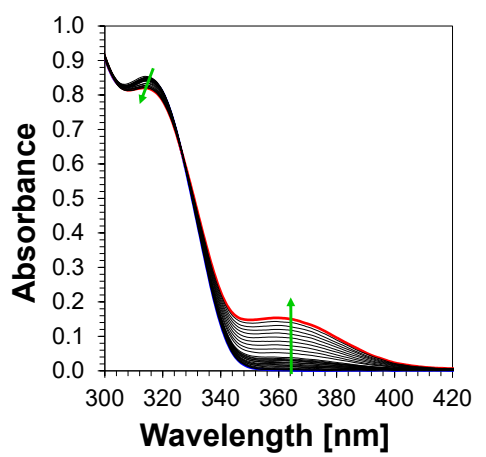

(c)

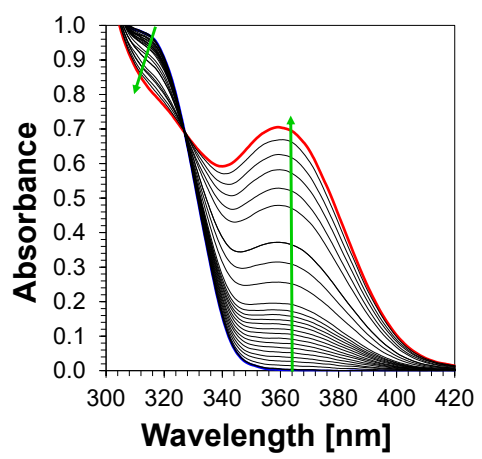

(f)

Figure 17. Photolysis of $\mathrm{HIP} / \mathrm{PT}-\mathrm{OCH}_{3}$ in acetonitrile upon exposure to LED @ $320 \mathrm{~nm}\left(1 \mathrm{~mW} / \mathrm{cm}^{2}\right)$ in a molar ratio: (a) $0.5: 1 ;$ (b) $1: 1$; (c) $5: 1$; (d) $10: 1$; (e) 20:1; (f) 30:1. 


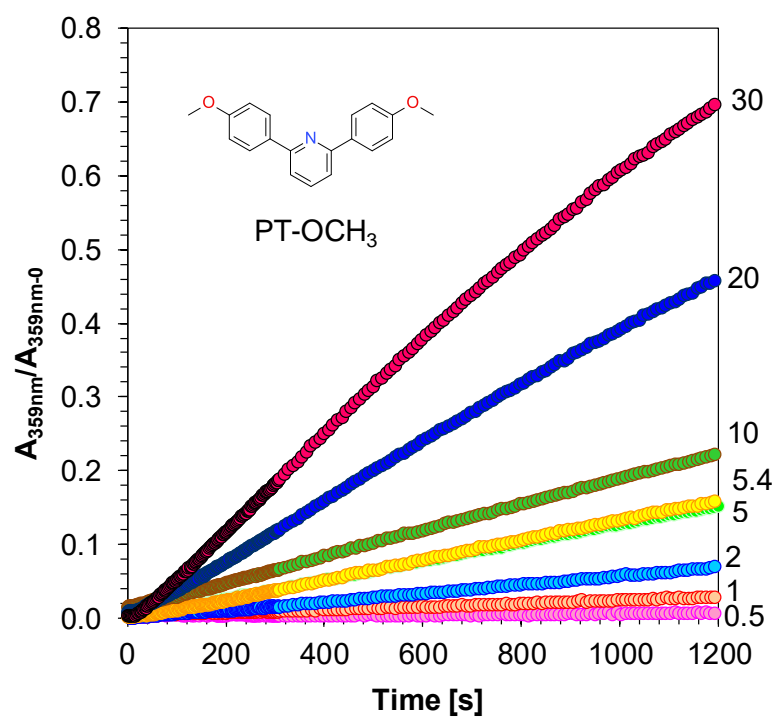

Figure 18. Profiles illustrating changes in absorbance over time of $\mathrm{PT}-\mathrm{OCH}_{3}$ at $320 \mathrm{~nm}\left(1 \mathrm{~mW} / \mathrm{cm}^{2}\right)$ upon adding various amounts of HIP photoinitiator using the $\mathrm{A}_{359 \mathrm{~nm}} / \mathrm{A}_{359 \mathrm{~nm}-0}$ parameter.

With decreasing $\mathrm{pH}$ and as the process of photocleavage of onium salt progresses, the fluorescence emission spectra, as well as absorption spectra of the sensors exhibited bathochromic shifts, resulting in large changes in emission ratios. It was found that the sensors are valuable for determining the progress of decomposition of cationic photoinitiators based on iodonium salts. The response of these sensors to process the photocleavage of photoinitiators relies on the $\mathrm{H}^{+}$binding with the $\mathrm{N}$ of pyridine and the induced enhancement of the ICT process.

\section{Conclusions}

In summary, new fluorescent molecular sensors based on 2,6-diphenylpyridine were designed and synthesised by introducing electron-donating or electron-withdrawing groups into the diphenylpyridine framework. The synthesis route of pyridines was a convenient and one-step synthesis via a bis Suzuki-Miyaura (SM) cross-coupling reaction. The applicability of a series of pyridine derivatives as molecular fluorescent sensors for monitoring free-radical and cationic photopolymerization by Fluorescence Probe Technology (FPT) was studied. From among the probes studied, only the 2,6-diphenylpyridines containing an electron-donating substituent at the phenyl rings shift their fluorescence spectrum to shorter wavelengths upon monomer polymerization far enough to enable the use of the fluorescence intensity ratio $(R)$ as the free-radical polymerization progress indicator. The R span of the remaining 2,6-diphenylpyridine derivatives is too small for practical applications; with these compounds, the normalised fluorescence intensity $\left(\mathrm{I} / \mathrm{I}_{0}\right)$, which is less versatile than $\mathrm{R}$, has to be used instead. In comparison to the 2-amino-4,6-diphenyl-pyridine-3-carbonitrile derivatives presented in a previous paper [49], the 2,6-diphenylpyridines are colorless compounds, which makes an unquestionable advantage. Therefore, 2,6-diphenylpyridine derivatives do not affect the colour of the formulations before and after the photopolymerization processes. They can be applied to photo-curing coating materials, such as varnishes, for which obtaining a highly transparent effect is extremely important from an industrial point of view. Consequently, the 2,6-diphenylpyridine derivatives can be used as fluorescent molecular sensors to monitor the progress of photopolymerization processes during production (i.e., on-line) without worrying about the effect on the final properties of the coating.

Nevertheless, fluorescence measurements during cationic photopolymerization indicated that all 2,6-diphenylpyridine derivatives could serve as sensitive sensors for $\mathrm{pH}$ measuring in acidic regions through colorimetric and fluorimetric changes. The significant bathochromic shift (around $90 \mathrm{~nm}$ ), good solubility in non-polar environmental, the sensitivity in the acidic range and extremely short response 
time under extreme acidic conditions of the probe makes it an interesting $\mathrm{pH}$ sensor. It is the belief of the authors that it will be greatly beneficial to study the effectiveness of the photodecomposition processes of cationic photoinitiators in order to evaluate the best molecule for this purpose. Therefore, 2,6-diphenylpyridine derivatives are a promising starting point for the development of efficient and versatile colorimetric and fluorescent molecular sensors for determining the effectiveness of the photo-cleavage processes of cationic photoinitiators. Understanding the reactivity of photoinitiators remains a simple way of designing more efficient molecules for the role of cationic photoinitiators, which is a fascinating topic from both an industrial as well as purely scientific point of view.

Supplementary Materials: The following are available online at http://www.mdpi.com/1424-8220/20/11/3043/s1, Figures S1-S16: ${ }^{1} \mathrm{H}$ NMR and ${ }^{13} \mathrm{C}$ NMR spectra of 2,6-diphenylpyridine derivatives; Figure S17: Synthesized compounds in powder form under: (a) sun light; (b) UV $254 \mathrm{~nm}$ light.; Figure S18: Synthesized compounds dissolved in acetonitrile under: (a) sun light; (b) UV 365 nm light; Figures S19-S24: Photolysis of 2,6-diphenylpyridine derivatives in ACN under 300nm $\left(26 \mathrm{~mW} / \mathrm{cm}^{2}\right)$; Figures S25-S31: Photolysis of 2,6-diphenylpyridine derivatives in ACN under 320 $\mathrm{nm}\left(1 \mathrm{~mW} / \mathrm{cm}^{2}\right)$; Figures S32-S38: Changes of fluorescence spectra of the 2,6-diphenylpyridine derivatives during free-radical photopolymerization of TMPTA monomer under irradiation $320 \mathrm{~nm}$; Figures S39-S40: Photolysis of HIP/PT-OCH $\mathrm{CH}_{3}$ molar ratio 2:1 and 5.4:1 in ACN upon exposure to LED $320 \mathrm{~nm}\left(1 \mathrm{~mW} / \mathrm{cm}^{2}\right)$.

Author Contributions: J.O. conceived the project, designed the research, designed the new sensors and contributed to all aspects of the study, analysed the whole dataset and wrote the final version of the paper. M.T. performed all the spectroscopic and photopolymerization experiments, assisted in analysing the whole dataset, prepared figures, wrote the draft version of the paper, and assisted in writing and editing the manuscript. F.P. and M.G. performed the synthesis of the different 2,6-diphenylpyridine derivatives reported in this work and characterized the chemical structures of these sensors by usual techniques. All authors have read and agreed to the published version of the manuscript.

Funding: This research was funded by the Foundation for Polish Science (Warsaw, Poland) grant number REINTEGRATION/2016-1/4 (POIR.04.04.00-00-1E42/16-00) "Synthesis and photochemistry/photophysics studies of the intelligent luminescent molecular sensors for selective detection in biochemistry and chemistry".

Conflicts of Interest: The authors declare no conflict of interest.

\section{References}

1. Czarnik, A.W. Fluorescent Chemosensors for Ion and Molecule Recognition; American Chemical Society: Washington, DC, USA, 1993.

2. Haidekker, M.A.; Brady, T.P.; Lichlyter, D.; Theodorakis, E.A. Effects of solvent polarity and solvent viscosity on the fluorescent properties of molecular rotors and related probes. Bioorg. Chem. 2005, 33, 415-425. [CrossRef] [PubMed]

3. Liu, D.; Deng, X.; Yin, X.; Wang, Y.; Guo, J.; Chen, J.; Yang, G.; He, H. 1,8-naphthalimide-based fluorescent sensor with high selectivity and sensitivity for $\mathrm{Zn}^{2+}$ and its imaging in living cells. Inorg. Chem. Commun. 2019, 11, 117-120. [CrossRef]

4. Liu, J.; Xu, C.; Yang, T.; Hu, Z.; Zhang, Z.; Feng, G. Developed a novel sensor based on fluorescent graft conjugated polymer for the determination of aristolochic acid in traditional Chinese medicine. Spectrochim. Acta A Mol. Biomol. Spectrosc. 2019, 222, 117239. [CrossRef] [PubMed]

5. Yin, P.; Niu, Q.; Yang, Q.; Lan, L.; Li, T. A new "naked-eye" colorimetric and ratiometric fluorescent sensor for imaging $\mathrm{Hg}^{2+}$ in living cells. Tetrahedron 2019, 75, 130687. [CrossRef]

6. Wu, D.; Sedgwick, A.C.; Gunnlaugsson, T.; Akkaya, E.U.; Yoon, J.; James, T.D. Fluorescent chemosensors: The past, present and future. Chem. Soc. Rev. 2017, 46, 7105-7123. [CrossRef]

7. De Acha, N.; Elosúa, C.; Corres, J.M.; Arregui, F.J. Fluorescent sensors for the detection of heavy metal ions in aqueous media. Sensors 2019, 19, 599. [CrossRef]

8. Kasprzyk, W.; Krzywda, P.; Bednarz, S.; Bogdał, D. Fluorescent citric acid-modified silicone materials. RSC Adv. 2015, 5, 90473-90477. [CrossRef]

9. Meng, X.J.; Zhao, J.Z.; Ma, W.B. Progress in fluorescent probes for $\mathrm{Cu}^{2+}$ and anions, neutral molecules sequential recognition. Chin. J. Org. Chem. 2020, 40, 276-283. [CrossRef] 
10. Chemchem, M.; Yahaya, I.; Aydıner, B.; Doluca, O.; Seferoğlu, N.; Seferoğlu, Z. Substituent dependent selectivity of fluorescent chemosensors derived from coumarin for biologically relevant DNA structures and anions. Sens. Actuat B Chem. 2019, 305, 127316. [CrossRef]

11. Wu, J.; Zou, Y.; Li, C.; Sicking, W.; Piantanida, I.; Yi, T.; Schmuck, C. A molecular peptide beacon for the ratiometric sensing of nucleic acids. J. Am. Chem. Soc. 2012, 134, 1958-1961. [CrossRef]

12. Morrison, A.O.; Gardner, J.M. Microscopic image photography techniques of the past, present, and future. Arch. Pathol. Lab. Med. 2015, 139, 1558-1564. [CrossRef] [PubMed]

13. De Silva, A.P.; Gunaratne, H.Q.N.; Gunnlaugsson, T.; Huxley, A.J.M.; McCoy, C.P.; Rademacher, J.T.; Rice, T.E. Signaling recognition events with fluorescent sensors and switches. Chem. Rev. 1997, 97, 1515-1566. [CrossRef] [PubMed]

14. Daly, B.; Ling, J.; de Silva, A.P. Current developments in fluorescent PET (photoinduced electron transfer) sensors and switches. Chem. Soc. Rev. 2015, 44, 4203-4211. [CrossRef] [PubMed]

15. Kwok, R.T.K.; Leung, C.W.T.; Lam, J.W.Y.; Tang, B.Z. Biosensing by luminogens with aggregation-induced emission characteristics. Chem. Soc. Rev. 2015, 44, 4228-4238. [CrossRef] [PubMed]

16. Merangmenla, A.P. Microwave-induced synthesis of a new benzodiazepinone based chemosensor in chloroform under thermal agitation: A potential fluorescent sensor for multi-signaling detection of metal ions. Inorg. Chim. Acta 2020, 505, 119520. [CrossRef]

17. Deems, J.C.; Reibenspies, J.H.; Lee, H.-S.; Hancock, R.D. Strategies for a fluorescent sensor with receptor and fluorophore designed for the recognition of heavy metal ions. Inorg. Chim. Acta 2020, 499, 119181. [CrossRef]

18. Liu, Y.; Ma, L.-N.; Shi, W.-J.; Lu, Y.-K.; Hou, L.; Wang, Y.-Y. Four alkaline earth metal (Mg, Ca, Sr, Ba)-based MOFs as multiresponsive fluorescent sensors for $\mathrm{Fe}^{3+}, \mathrm{Pb}^{2+}$ and $\mathrm{Cu}^{2+}$ ions in aqueous solution. J. Solid State Chem. 2019, 277, 636-647. [CrossRef]

19. Song, H.; Liu, G.; Fan, C.; Pu, S. A novel fluorescent sensor for $\mathrm{Al}^{3+}$ and $\mathrm{Zn}^{2+}$ based on a new europium complex with a 1,10-phenanthroline ligand. J. Rare Earths 2020. [CrossRef]

20. Majidi, B.; Amiri, A.; Badiei, A.; Shayesteh, A. Dual mode colorimetric-fluorescent sensor for highly sensitive and selective detection of $\mathrm{Mg}^{2+}$ ion in aqueous media. J. Mol. Struct. 2020, 1213, 128156. [CrossRef]

21. Ortyl, J.; Galek, M.; Milart, P.; Popielarz, R. Aminophthalimide probes for monitoring of cationic photopolymerization by fluorescence probe technology and their effect on the polymerization kinetics. Polym. Test. 2012, 31, 466-473. [CrossRef]

22. Kamińska, I.; Ortyl, J.; Popielarz, R. Applicability of quinolizino-coumarins for monitoring free radical photopolymerization by fluorescence spectroscopy. Polym. Test. 2015, 42, 99-107. [CrossRef]

23. Vatanparast, R.; Li, S.; Hakala, K.; Lemmetyinen, H. Monitoring of curing of polyurethane polymers with fluorescence method. Macromolecules 2000, 33, 438-443. [CrossRef]

24. Itagaki, H.; Horie, K.; Mitra, I. Luminescent probe studies of the microstructure and mobility of solid polymers. Prog. Polym. Sci. 1990, 15, 361-424. [CrossRef]

25. Ortyl, J.; Wilamowski, J.; Milart, P.; Galek, M.; Popielarz, R. Relative sensitization efficiency of fluorescent probes/sensitizers for monitoring and acceleration of cationic photopolymerization of monomers. Polym. Test. 2015, 48, 151-159. [CrossRef]

26. Valeur, B. Molecular Fluorescence Principles and Applications; Wiley-VCH Verlag GmbH: Weinheim, Germany, 2001.

27. Berezin, M.Y.; Achilefu, S. Fluorescence lifetime measurements and biological imaging. Chem. Rev. 2010, 110, 2641-2684. [CrossRef]

28. Pączkowski, J. Fluorescent probes as a research tool in polymer chemistry. Polimery 2005, 50, 520-529. [CrossRef]

29. Pączkowski, J.; Neckers, D.C. Following polymerization kinetics of multifunctional acrylates in real time by fluorescence probe methodology. Macromolecules 1992, 25, 548-553. [CrossRef]

30. Grabowski, Z.; Rotkiewicz, K.; Retting, W. Structural changes accompanying intramolecular electron transfer: focus on twisted intramolecular charge-transfer states and structures. Chem. Rev. 2003, 103, 3899-4032. [CrossRef]

31. Loutfy, R.O.; Arnold, B.A. Effect of viscosity and temperature on torsional relaxation of molecular rotors. J. Phys. Chem. 1982, 86, 4205-4211. [CrossRef]

32. Loutfy, R.O. Fluorescence probes for polymer free-volume. Pure Appl. Chem. 1986, 58, 1239-1248. [CrossRef] 
33. Warman, J.M.; Abellon, R.D. Maleimido-fluoroprobe: A dual-purpose fluorogenic probe of polymerization dynamics. J. Phys. Chem. B 1997, 101, 4913-4916. [CrossRef]

34. Bajorek, A.; Trzebiatowska, K.; Jędrzejewska, B.; Pietrzak, M.; Gawinecki, R.; Paczkowski, J. Developing of fluorescence probes based on stilbazolium salts for monitoring free radical polymerization processes. II. J. Fluoresc. 2004, 14, 295-307. [CrossRef] [PubMed]

35. Wight, F.R.; Hicks, G.W. Applications of differential scanning calorimetry to photocurable polymer systems. Polym. Eng. Sci. 1978, 18, 378-381. [CrossRef]

36. Jiang, F.; Drummer, D. Curing kinetic analysis of acrylate photopolymer for additive manufacturing by Photo-DSC. Polymers 2020, 12, 1080. [CrossRef]

37. Jakubiak, J.; Sionkowska, A.; Lindén, L.-Å.; Rabek, J.F. Isothermal photo differential scanning calorimetry. Crosslinking polymerization of multifunctional monomers in presence of visible light photoinitiators. J. Therm. Anal. Calorim. 2001, 65, 435-443. [CrossRef]

38. Chiou, B.-S.; Khan, S.A. Real-Time FTIR and in situ rheological studies on the UV curing kinetics of thiol-ene polymers. Macromolecules 1997, 30, 7322-7328. [CrossRef]

39. Kim, Y.-M.; Kostanski, L.K.; MacGregor, J.F.; Hamielec, A.E. Thermal and real-time FTIR spectroscopic analysis of the photopolymerization of diepoxide-vinyl ether mixtures. J. Therm. Anal. Calorim. 2004, 78, 153-164. [CrossRef]

40. Raja, T.N.; Brouwer, A.M. Fluorescence spectroscopy in polymer science. In Advanced Fluorescence Reporters in Chemistry and Biology III: Applications in Sensing and Imaging; Demchenko, A.P., Ed.; Springer: Berlin, Germany, 2011; Volume 10, pp. 91-117.

41. Ortyl, J.; Popielarz, R. The performance of 7-hydroxycoumarin-3-carbonitrile and 7-hydroxycoumarin-3carboxylic acid as fluorescent probes for monitoring of cationic photopolymerization processes by FPT. J. Appl. Polym. Sci. 2012, 128, 1974-1978. [CrossRef]

42. Jager, W.F.; Sarker, A.M.; Neckers, D.C. Functionalized 4-(dialkylamino)-4'-nitrostilbenes as reactive fluorescent probes for monitoring the photoinitiated polymerization of MMA. Macromolecules 1999, 32, 8791-8799. [CrossRef]

43. Ortyl, J.; Galica, M.; Popielarz, R.; Bogdał, D. Application of a carbazole derivative as a spectroscopic fluorescent probe for real time monitoring of cationic photopolymerization. Pol. J. Chem. Technol. 2014, 16, 75-80. [CrossRef]

44. Yeow, J.; Joshi, S.; Chapman, R.; Boyer, C.A. Self-reporting photocatalyst for online fluorescence monitoring of high throughput RAFT polymerization. Angew. Chem. Int. Ed. 2018, 57, 10102-10106. [CrossRef] [PubMed]

45. Bosch, P.; Catalina, F.; Corrales, T.; Peinado, C. Fluorescent probes for sensing processes in polymers. Chem. Eur. J. 2005, 11, 4314-4325. [CrossRef] [PubMed]

46. Medel, S.; Bosch, P. New fluorescent hyperbranched polymeric sensors as probes for monitoring photopolymerization reactions. React. Funct. Polym. 2015, 93, 101-110. [CrossRef]

47. Evingür, G.A.; Kaygusuz, H.; Erim, F.B.; Pekcan, Ö. Gelation of PAAm-PVP composites: A fluorescence study. Int. J. Mod. Phys. B. 2014, 28, 1450122. [CrossRef]

48. Sawicz-Kryniger, K.; Popielarz, R. Comparison of the effectiveness of epoxy cure accelerators using a fluorescent molecular probe. Polym. Test. 2013, 32, 1558-1564. [CrossRef]

49. Ortyl, J.; Fiedor, P.; Chachaj-Brekiesz, A.; Pilch, M.; Hola, E.; Galek, M. The applicability of 2-amino-4,6diphenyl-pyridine-3-carbonitrile sensors for monitoring different types of photopolymerization processes and acceleration of cationic and free-radical photopolymerization under near UV light. Sensors 2019, 19, 1668. [CrossRef]

50. Ortyl, J.; Topa, M.; Kamińska-Borek, I.; Popielarz, R. Mechanism of interaction of aminocoumarins with reaction medium during cationic photopolymerization of triethylene glycol divinyl ether. Eur. Polym. J. 2019, 116, 45-55. [CrossRef]

51. Reynolds, L.; Gardecki, J.A.; Frankland, S.J.V.; Horng, M.L.; Maroncelli, M. Dipole solvation in nondipolar solvents: Experimental studies of reorganization energies and solvation dynamics. J. Phys. Chem. 1996, 100, 10337-10354. [CrossRef]

52. Ortyl, J.; Milart, P.; Popielarz, R. Applicability of aminophthalimide probes for monitoring and acceleration of cationic photopolymerization of epoxides. Polym. Test. 2013, 32, 708-715. [CrossRef] 
53. Kamińska, I.; Ortyl, J.; Popielarz, R. Mechanism of interaction of coumarin-based fluorescent molecular probes with polymerizing medium during free radical polymerization of a monomer. Polym. Test. 2016, 55, 310-317. [CrossRef]

54. McDaniel, D.H.; Brown, H.C. An extended table of Hammett substitutent constants based on the ionization of substituted benzoic acids. J. Org. Chem. 1958, 23, 420-427. [CrossRef]

55. Yuan, C.; Zhang, Y.; Xi, H.; Tao, X. An acidic pH fluorescent probe based on Tröger's base. RSC Adv. 2017, 7, 55577-55581. [CrossRef]

(C) 2020 by the authors. Licensee MDPI, Basel, Switzerland. This article is an open access article distributed under the terms and conditions of the Creative Commons Attribution (CC BY) license (http://creativecommons.org/licenses/by/4.0/). 